Portland State University

PDXScholar

\title{
An Introductory Overview of the Koyukon (Athabaskan) Verb
}

Jonathan K. Vincent

Portland State University

Follow this and additional works at: https://pdxscholar.library.pdx.edu/honorstheses

Part of the Language Description and Documentation Commons, and the Morphology Commons Let us know how access to this document benefits you.

Recommended Citation

Vincent, Jonathan K., "An Introductory Overview of the Koyukon (Athabaskan) Verb" (2020). University Honors Theses. Paper 925.

https://doi.org/10.15760/honors.947

This Thesis is brought to you for free and open access. It has been accepted for inclusion in University Honors Theses by an authorized administrator of PDXScholar. Please contact us if we can make this document more accessible: pdxscholar@pdx.edu. 
An Introductory Overview of the Koyukon (Athabaskan) Verb

by

Jonathan K. Vincent

An undergraduate thesis submitted in partial fulfillment of the requirements for the degree of

Bachelor of Arts

in University Honors

and Applied Linguistics and German

Thesis Advisor

Steven L. Thorne, Ph.D.

Portland State University 


\section{CONTENTS}

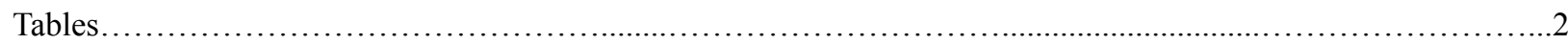

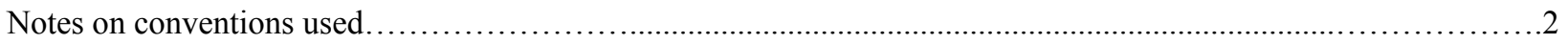

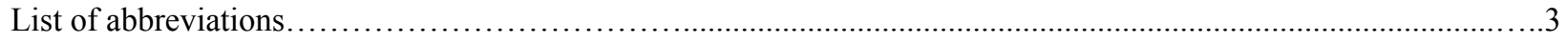

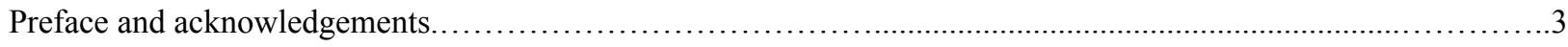

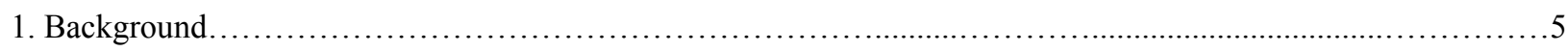

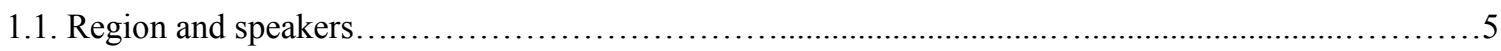

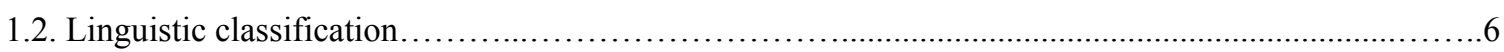

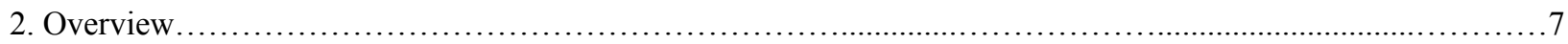

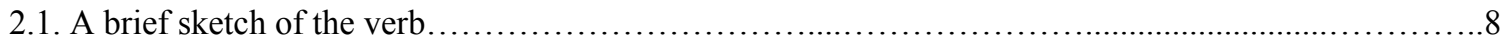

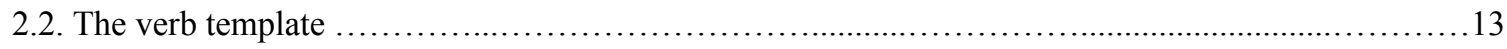

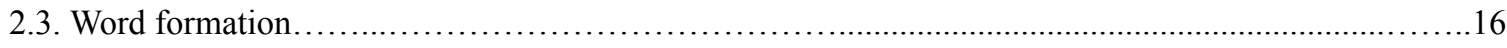

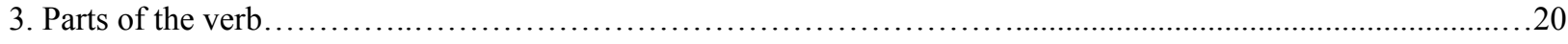

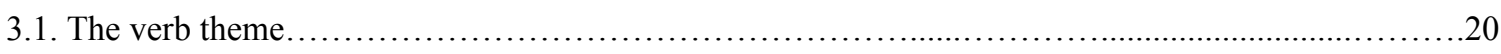

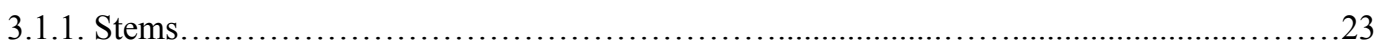

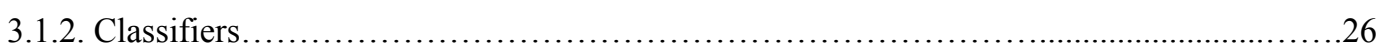

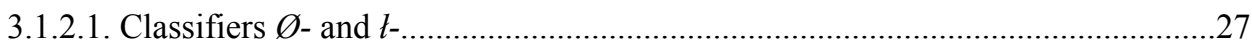

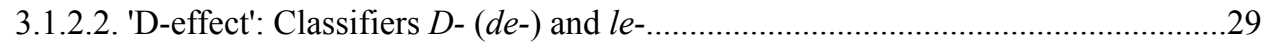

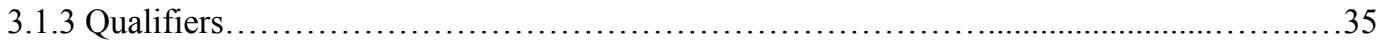

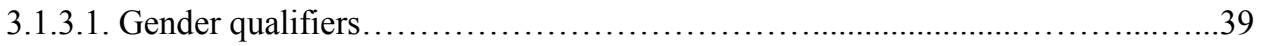

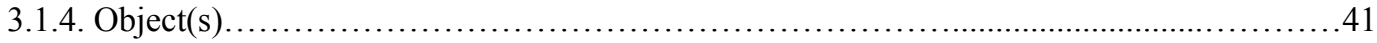

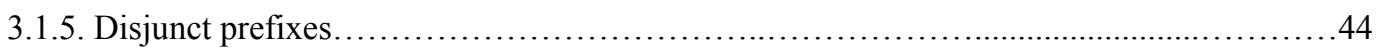

3.1.5.1. Thematic prefixes and incorporates............................................. 45

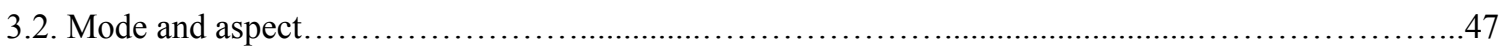

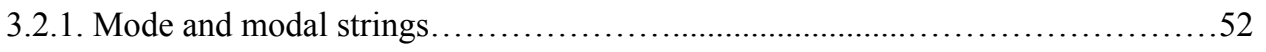

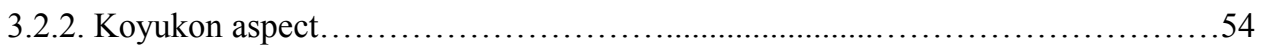

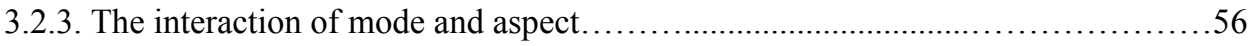

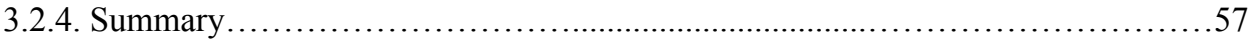

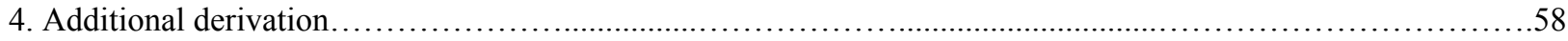

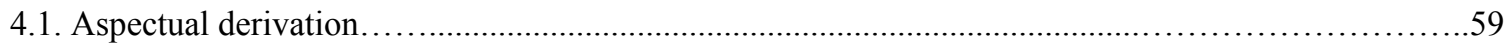

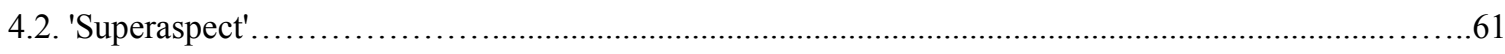

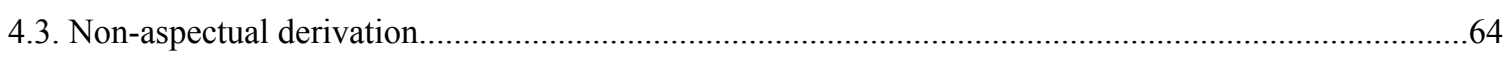

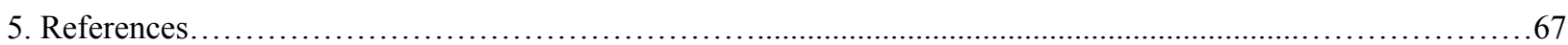




\section{Tables}

Table 1. Standard Koyukon orthography to phonetic alphabet (IPA)........................................

Table 2. Classification of Koyukon.....................................................................

Table 3. Truncated Koyukon verb template ......................................................................14

Table 4. Word formation in Athabaskan, as proposed by Kari (1992).....................................18

Table 5. Word formation exemplified with bet\#ne+le+ten 'to fall asleep' '.................................19

Table 6. Verb themes with either $\emptyset$ - or 1 - classifiers...............................................................27

Table 7. The six genders of Koyukon and their qualifier prefixes/noun class markers................40

Table 8. Object pronoun prefixes in Koyukon ........................................................................41

Table 9. Nine mode-conveying affix strings in Koyukon.......................................................53

Table 10. Koyukon aspect by governed perfective modal prefix category..................................57

\section{Notes on conventions used}

The choice of conventions for representing Koyukon data was constrained on the one hand to be as thoroughly descriptive as possible, while on the other hand to be maximally approachable for readers that may not be Athabaskanists or language specialists. To appease the former, I have made use of morpheme-by-morpheme glosses in general accordance with the Leipzig glossing rules ${ }^{1}$ to illustrate the morphemic composition of Koyukon verbs. To accommodate the latter, I have opted to use the orthography used in the Koyukon Athabaskan Dictionary (Jetté et al., 2000) over the more esoteric international phonetic alphabet (IPA). For those interested in the IPA correspondence with the Koyukon orthography, see the table below, which is followed by a list of abbreviations used in this paper.

\footnotetext{
${ }^{1}$ For more on the Leipzig glossing rules, which are used to standardize the representation of morpho-syntactic information in language-specific data, see https:/www.eva.mpg.de/lingua/pdf/Glossing-Rules.pdf.
} 
Table 1. Standard Koyukon orthography to phonetic alphabet (IPA).

\begin{tabular}{|c|c|c|c|c|}
\hline Vowels: & Consonants: & & & \\
\hline$<\mathrm{aa}>-/ \mathfrak{a}: /$ & $<\mathrm{b}>-/ \mathrm{p} /$ & $<\mathrm{k}>-/ \mathrm{k}^{\mathrm{h} /}$ & $<\mathrm{ts}>-/ \mathrm{ts}^{\mathrm{h}} /$ & $<\mathrm{s}>-/ \mathrm{s} /$ \\
\hline$<\mathrm{ee}>-$ /i:/ & $<\mathrm{d}>-/ \mathrm{d} /$ & $<\mathrm{k}^{\prime}>-/ \mathrm{k}^{\prime} /$ & $<\mathrm{ts}^{\prime}>-/ \mathrm{ts}^{\prime} /$ & $<\mathrm{z}>-\mid \mathrm{z} /$ \\
\hline$<\mathrm{oo}>-/ \mathrm{u}: /$ & $<\mathrm{dl}>-/ \mathrm{tt} /$ & $<\mathrm{kk}>-/ \mathrm{q}^{\mathrm{h}} /$ & $<1>-/ 1 /$ & $<\mathrm{h}>-|\mathrm{x} \sim \chi|$ \\
\hline$<0>-/ 0: /$ & $<\mathrm{dz}>-/ \mathrm{ts} /$ & $<\mathrm{t}>-/ \mathrm{t}^{\mathrm{h}} /$ & $<\mathrm{t}>-/ \mathrm{t} /$ & $<\mathrm{y}>-/ \mathrm{c} \sim \mathrm{y} /$ \\
\hline$<\mathrm{e}>-/ \mathrm{a} /$ & $<\mathrm{g}>-/ \mathrm{k} /$ & $\left\langle\mathrm{t}^{\prime}\right\rangle-\mid \mathrm{t}^{\prime} /$ & $<\mathrm{m}>-/ \mathrm{m} /$ & $<\mathrm{yh}>-\mid \mathrm{j} \sim \mathrm{j} / \mathrm{x} /$ \\
\hline$<\mathrm{u}>-/ \mathrm{v} /$ & $<\mathrm{gh}>-/ \mathrm{J} \sim \mathrm{G} /$ & $<\mathrm{tl}>-/ \mathrm{t}^{\mathrm{h}} /$ & $<\mathrm{n}>-/ \mathrm{n} /$ & $<^{i}>-/\left.2\right|^{\circ}$ \\
\hline$<_{\mathbb{H}}>-\mid \mathrm{B} /$ & $<\mathrm{gg}>-/ \mathrm{q} /$ & $<\mathrm{tl}^{\prime}>-/ \mathrm{tl}^{\prime} /$ & $<\mathrm{nh}>-/ \mathrm{n} /$ & \\
\hline
\end{tabular}

\section{List of abbreviations}

Aspects:

$\begin{array}{ll}\text { BIS } & \text { bisective } \\ \text { CNCL } & \text { conclusive } \\ \text { CONS } & \text { consecutive } \\ \text { CONT } & \text { continuative } \\ \text { DIR-REP } & \text { directive-repetitive } \\ \text { DUR } & \text { durative } \\ \text { MOM } & \text { momentaneous } \\ \text { NEU } & \text { neuter } \\ \text { ONO } & \text { onomatopoetic } \\ \text { PERS } & \text { persistive } \\ \text { PRMB } & \text { perambulative } \\ \text { REP } & \text { repetitive } \\ \text { REV } & \text { reversative } \\ \text { SEM } & \text { semelfactive } \\ \text { TRNS } & \text { transitional } \\ & \\ \text { Inflection: } & \\ & \\ \text { 1SG.SUBJ } & \text { first-person subject } \\ \text { 1SG.OBJ } & \text { first-person object } \\ \text { 3SG.SUBJ } & \text { third-person subject } \\ \text { 3SG.OBJ } & \text { third-person object } \\ \text { INDEF.OBJ } & \text { indefinite object }\end{array}$

Modes:

M mode

IMPRF imperfective

PRF perfective

OPT optative

FUT future

Superaspects:

CUST customary

DIST distributive

MULT multiple

PROG progressive
Theme:

CL classifier

$\mathrm{CL}_{\varnothing} \quad$ Ø-classifier

$\mathrm{CL}_{1} \quad$ t-classifier

$\mathrm{CL}_{\varnothing+\mathrm{D}} D$-, de-classifier

$\mathrm{CL}_{\mathrm{H}+\mathrm{D}}$ le-classifier

QUAL qualifier

$\mathrm{T}$ thematic prefix

O object

G (object) gender

$\mathrm{P}$ postpositional object

PP postposition

Derivation:
DS derivational string

ITER interative

RECIP reciprocal

INCEP inceptive 


\section{Preface and acknowledgements}

In 2000, the Alaska Native Language Center at the University of Alaska, Fairbanks published an extensive dictionary of the Koyukon language, thereby tying together efforts that stretched from the Jesuit missionary Jules Jetté in Nulato at the beginning of the twentieth century to the concentrated efforts of those at the ANLC, among them Eliza Jones, Jim Kari, Michael Krauss, and Melissa Axelrod. It is on the dedicated work by these linguists that this humble overview is based. All example sentences and words, unless otherwise specified, come directly from that dictionary. These authors are, of course, not responsible for any of the faults in my analysis, nor in the many morpheme glosses which I have imposed over their data.

The Koyukon dictionary is impressive by all measures, but in its compact thoroughness, it is virtually impenetrable to even the most devoted of 'readers' - especially students and those who are not language professionals. The work's primary function as a dictionary understandably overrides what might have been a more effective organization for purposes of introducing someone to the grammatical complexities of an Athabaskan language. The authors of the KAD foresaw the potential difficulties of decoding its contents, writing "For primary educational purposes, it will of course be necessary to develop a whole generation, so to speak, of appropriate materials" (Jetté et al., 2000: 1xxx). This overview of the Koyukon verb might be considered, I hope, a small step in the direction of opening up Athabaskan linguistics to others none more important than the heritage learners and speakers of Koyukon and other Athabaskan languages.

I am indebted to the positive intellectual influence and support of my mentors at Portland State University. Among these are Dr. Tony Lewis, for his unrelenting kindness and many 
motivating words, as well as the generosity with which he includes me in his network of scholars and dedicated community members. I also owe gratitude to Dr. Tucker Childs, from whose teachings I have learned a great deal, especially in matters related to the urgency of language endangerment. With a great deal of respect, I thank Dr. Steve Thorne for his commitment to me and this project (as a scholar as well as my advisor). His scholastic and personal energy has enlivened my work, and his enlightened perspective on issues of language revitalization and beyond has shown me the direction in which I hope to grow. Finally, I wish to express my respect and appreciation for the speakers of Denaakk'enaage' and their children. May they all live long lives.

\section{Background}

Before proceeding into an overview and explanation of Koyukon's verbal morphology, an account of where and by whom Koyukon is spoken, as well as how Koyukon is related to neighboring and other more distant languages, is in order.

\subsection{Region and speakers}

Denaakke(naage'), known more widely by the anglonym 'Koyukon,' is a language spoken in several villages along the Yukon River and its tributaries in interior Alaska, west of Fairbanks. The geographical region in which Koyukon has been spoken spans from Steven's Village and Beaver, 100 miles north of Fairbanks, downriver to Kaltag and Grayling in the Southwest, 400 miles west-southwest of Fairbanks. In terms of neighboring languages, the Koyukon region is bordered by Gwich'in to the Northeast, Lower Tanana and Ahtna to the Southeast, Upper 
Kuskokwim to the South, Holikachuk to the Southwest, and Yupik and Inupiaq to the West and North.

In the fifteen villages that lie within this region, the estimated total population as of the year 2000 was just over two thousand (Krauss, 2000: liv). While the population has not likely changed drastically over the last twenty years, the number of speakers estimated by Krauss (2000), around 275, has likely fallen greatly in that time. As an instance of this, the estimated number of Koyukon speakers in Nulato, just upriver from Kaltag, has fallen from around 45 in the year 2000 to less than ten in 2020, all of whom are now over the age of 75 . This gloom trend is likely typical for the other fourteen villages, and is a grim reflection of the sobering trends of linguistic decline across Alaska, North America, and the world (Krauss, 1992; Counceller et al., 2020; Kari and Spolski, 1978).

\subsection{Linguistic classification}

Table 2. Classification of Koyukon.

$$
\begin{aligned}
& \text { Na-Dene (phylum) } \\
& \text { >Athabaskan (genus) } \\
& \text { >Northern Athabaskan (sub-genus) } \\
& >\text { Central Alaskan-Yukon (sub-group) } \\
& \text { >Koyukon/Denaak'e(naage') (language) }
\end{aligned}
$$

Koyukon belongs to the Central Alaskan-Yukon geographical group of the Northern Athabaskan sub-genus. This sub-group also includes the closely related Holikachuk and Deg Xinag, the more distantly related Upper Kuskokwim, Lower Tanana, Upper Tanana, Tanacross, Tutchone, and the distantly related Gwich'in and Hän. These languages, and several more in 
Western and Northwestern Canada and Alaska, constitute the Northern Athabaskan sub-genus of the Athabaskan family.

The Athabaskan family, in addition to the Northern region, also subsumes the Pacific Coast sub-genus, which includes the Tolowa, Upper Umpqua, and Upper and Lower Rogue River languages of Oregon as well as Hupa, Mattole-Bear River, Wailaki, and Cahto of California. The Athabaskan family also subsumes the Southern sub-genus, which includes Plains and Western Apache, Chiricahua, Mescalero, Jicarilla, Lipan, and Navajo.

The Athabaskan genus is closely related to the neighboring Eyak language, and the family that they constitute (i.e., Athabaskan-Eyak) is more distantly related to the Tlingit language. These three language groups constitute the Na-Dene family, first proposed by Edward Sapir in 1915 (Sapir, 1915). The Na-Dene family does not include neighboring Haida or Tsimshian, as both of these languages are isolates, unrelated to any other language but themselves. The Na-Dene family also does not include the neighboring Aluet or Inuit-Yupik families.

\section{Overview}

Verbs in Athabaskan languages such as Koyukon are tasked with encoding a considerable amount of both grammatical and semantic information, compared both to verbs in other language groups (even others in North America), and to other word categories within Athabaskan languages. The robustness of Koyukon's verbal morphology is apparent not just in its overall structural complexity, but also in its communicative function, enabling speakers to describe states of being and actions and, to a lesser extent, the nominal entities (i.e., people and objects) 
involved in those actions to a remarkable degree of specificity and semantic nuance. Both the categorical breadth and depth of the Koyukon verb's morphological capacity and function grant the verb a particularly vital role in the Koyukon language. Because the Koyukon verb is so uniquely equipped to perform a great deal of communicative work, and because this verbal complexity is remarkably consistent within the Athabaskan language family, an overview of the Koyukon verb is both appropriate and may lend itself as a good introduction to the complexities that are characteristic of the Athabaskan language family as a whole.

This section will provide a brief summary of the basic form of the Koyukon verb, then will proceed into an introduction of the theoretical framework for conceptualizing how those components are ordered. This is then followed by an exploration of how these components may be grouped into separable units, and how those groups interact with one another on an abstract level (i.e., word formation). The remaining sections are devoted to a more in-depth analysis of the verb's many types of constituents and the interlocking systems into which they fit.

\subsection{A brief sketch of the verb}

Among the more striking aspects of Athabaskan verbal morphology is the sheer amount of grammatical categories within which any given verb distinguishes. Koyukon verbs are invariably polymorphemic (i.e., multi-parted), obligatorily marking for voice/valency (e.g., passive, causative), tense, mood, aspect, and both subject and object. In addition to these categories, additional morphology may modify a verb to emphasize or introduce focus on the duration, direction, location, or even success of an action, among other possibilities. These 
grammatical categories, the interaction between them, and their representation on the surface level all contribute to the complexity of the Koyukon verb.

The many distinctions expressed by a verb are made mostly, though not completely, by a number of affixes, most of which prefix onto the verb stem. The transparency of the fusional process (i.e., the discernibility of the boundaries between morphemes) is complicated by a number of morpho-phonological processes which, for example, delete some morphemes from, or irregularly add morphemes to, the surface level, and leave others to assimilate each other in various ways. The complexity of a verb's many constituents is thus compounded by their phonologically obscured arrangement.

The alignment (i.e., exponence) between categories and their respective morphemes is, unsurprisingly, not straightforward in Koyukon. A single category may be implicated by a number of morphemes (i.e., extended exponence), while a single syllable may provide values for multiple categories (i.e., cumulative exponence). Consider the following examples of grammatical verbs in Koyukon and their translations.

(1) a. ledo

'(S)he stays'

b. yengheel'aan'

'(S)he saw him'

c. sooł'aanh

'(S)he is waiting for me to act'

d. yeebełk'enaadletenh

'(S)he fell into a deep sleep'

e. todekenhdegheetonh

'(S)he put a stick in the water' 
Although the morphological complexity of these verbs varies, as does the scope of their meanings, they share a number of things in common. In terms of their function alone, each of the verbs above communicates at least (1) what is being done and (2) by whom, (3) whether or not they have completed doing it, and (4) whether or not doing so affects someone or something. This more or less comprehensive propositional schematic can then be modified, as will be seen, in order to suppress or involve more participants, imply certain physical traits about those participants, and/or specify the nature of the action denoted by a verb.

In basic terms of their structure, each of the verbs above is made up of a stem and a number of prefixes ${ }^{2}$ which serve a wide variety of functions. Some prefixes categorize the action of the verb in grammatical terms of completion, duration, and desirability, among others, as well as mark for person. Other prefixes modify or help supply the semantics of the verb base. These prefixes have been categorized in Athabaskanist literature into several groups or 'zones,' defined on the basis of both distribution (i.e., their position in relation to the stem and other morphemes) as well as common general function.

An important and unavoidable observation with which any analysis must begin is that the semantic foundation of a given verb is not always attributable solely to the verb root. Consider, for example, the following verbs; both of which contain the same verb stem -dek in the final syllable.
a. nek'edenaatldek
'(S)he wrote something (letter, word)'
b. noyegheełdek
'(S)he shot it down with an arrow'

\footnotetext{
${ }^{2}$ Full templates of Athabaskan verbs outline as many as twenty-five or so possible prefix positions, although naturally occurring verbal utterances with anywhere near that number are quite rare.
} 
As these two verbs ${ }^{3}$ make clear, the stem alone cannot serve as the building block of the Koyukon lexicon. Clearly, some of the affixual elements of a verb share a responsibility with the stem to constitute the basic lexeme for any one verb. This unit (i.e., the minimal verbal unit) in Athabaskan languages is what is known as a 'verb theme.'

A verb theme consists of a stem and a small number of prefixes that are present in every derivative of a verb with one meaning. Thematic prefixes - that is, those required by a verb theme - vary in how transparent they are with respect to their individual function. A need to discern those functions, however, is conveniently precluded by the notion of the verb theme. In other words, because verb themes are taken to be the minimal unit in the Koyukon lexicon, meaning need not be — if possible at all — divided and ascribed to any one part of the verb theme.

Although lexical meaning cannot be administered to any one part of the theme, various phono-morphological and grammatical processes treat those parts differently. In order to understand these processes, which affect the form and meaning of the verb as a whole, constituents of the verb theme may be considered on their own individual functional terms. Out of this need to understand these processes, the grammatical function of each part of the verb theme is outlined in some detail in section 3. However, a very brief outline of these parts may be in order before returning to some examples of verbs.

The prefix to the immediate left of the stem, the verb 'classifier' (not to be confused with noun classifiers), is a part of the verb theme, and implicates the valency, or argument structure, of the verb. In addition to the classifier, another prefix, the 'qualifier,' provides a much less

\footnotetext{
${ }^{3}$ As stated in the preface, all examples used in this paper, unless otherwise specified, come from the Koyukon Athabaskan Dictionary (Jetté et al., 2000).
} 
transparent meaning to the verb theme. These prefixes were likely adverbial elements at one time, but have since been effectively 'lexicalized' onto a specific verb to collectively supply a single meaning (i.e., the theme). Some verb themes require more prefixes which are relatively productive elsewhere in the language. Unlike qualifiers, these prefixes, which shall by termed generally 'thematic,' may be noun stems which have been incorporated into the verb (via a process generally known as 'polysynthesis'), or a postpositional phrase. Finally, transitive verb themes require their objects and often their respective noun class markers (henceforth 'genders'), which serve as agreement markers within the verb. These components (i.e., stem, classifier, qualifier(s), thematic prefix(es), and object/gender) construct a morphological skeletal structure for a word. ${ }^{4}$

A minimal grammatical utterance must contain a verb theme that has been fleshed out with inflection and mode. The obligatory categories together include subject, tense, mood, and aspect. Multiple prefixes are tasked with encoding these categories, especially aspect (see section 3.2.). The elements which mark for these inflectional (and modal) categories are not affixed onto either side of the verb base, but are instead situated throughout the elements of the verb theme. A verb theme thus becomes a discontinuous base at the surface level, much like languages that exhibit 'root and pattern' morphology like Arabic and Hebrew. However, the similarities stop there, given that verb theme constituents are analyzable as having separate functions, generally speaking.

\footnotetext{
${ }^{4}$ The notion of a 'word' is a complicated matter in discussions of so-called 'polysynthetic' languages like those belonging to the Athabaskan family (Rice, 2000). Some Koyukon verbs, if not most, for example, have meanings that are only translatable into English as full clauses (i.e., with multiple English words). The concept of a 'word' may therefore not be a particularly useful unit of analysis for Koyukon, at least from a standpoint of syntax.
} 
In addition to the verb theme and obligatory inflection, verbs may also be modified with derivational morphology. Much of this derivation is aspectual, providing information about the perception of the intention, quality, duration, or other circumstance of the action expressed by the verb theme. These complex aspectual derivations are most often achieved through the coordination of multiple discontinuous elements, much like verb themes (although lacking stems), which, like inflection morphology, interweave themselves into the verb complex.

With these structural principles of the verb laid out, a consideration of the order in which they appear in a verb may be useful.

\subsection{The verb template}

Although Koyukon verbs display a high degree of morphological (i.e., affixual) variability, the ordering of those elements is assuringly more rigid. In all affixual variations, morphemes strongly tend to appear in the same position in relation to (i.e., left or right of) the stem and/or other morphemes. Compare, for example, the following two verbs and their respective morpheme-breakdowns. ${ }^{5}$

a. seneel'aanh

$$
\begin{aligned}
& \text { se- } \quad n e-\quad(n) e-\varnothing-\quad t-\quad \text { 'aan } \quad-(n) h \\
& \text { 1SG.OBJ- QUAL-M } \mathrm{PRF}^{-} \text {3SG.SUBJ- } \mathrm{CL}_{-}-\text {look.DUR -IMPRF }
\end{aligned}
$$

' $(\mathrm{S})$ he is looking at me'

b. yeetltseenh

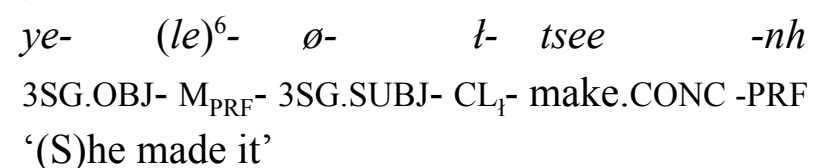

\footnotetext{
${ }^{5}$ See section List of abbreviations at the top for morpheme abbreviations.

${ }^{6}$ Here, the morphemes $l e$ - and $t$ - have assimilated one another to produce the surface form $e t t$-. These morpho-phonological rules regrettably escape the scope of this study, but will be footnoted thusly whenever relevant.
} 
The two verbs in (3), meaning '(S)he is looking at me' and '(S)he made it' respectively, are structurally similar in revealing ways. With the exception of the qualifier in $a$., which is lacking in $b$, both verbs have, moving right to left, (1) a stem and suffix, (2) a verb 'classifier,' (3) a subject marker (phonologically null for the third-person singular), (4) a modal prefix, and (5) a direct object pronoun (see section 3 for definitions and further examples of all of these components). Most importantly, they both place each of these components in the same linear order. If this order were to be schematized, the following template ${ }^{7}$ may be suggested:

Table 3. Truncated Koyukon verb template.

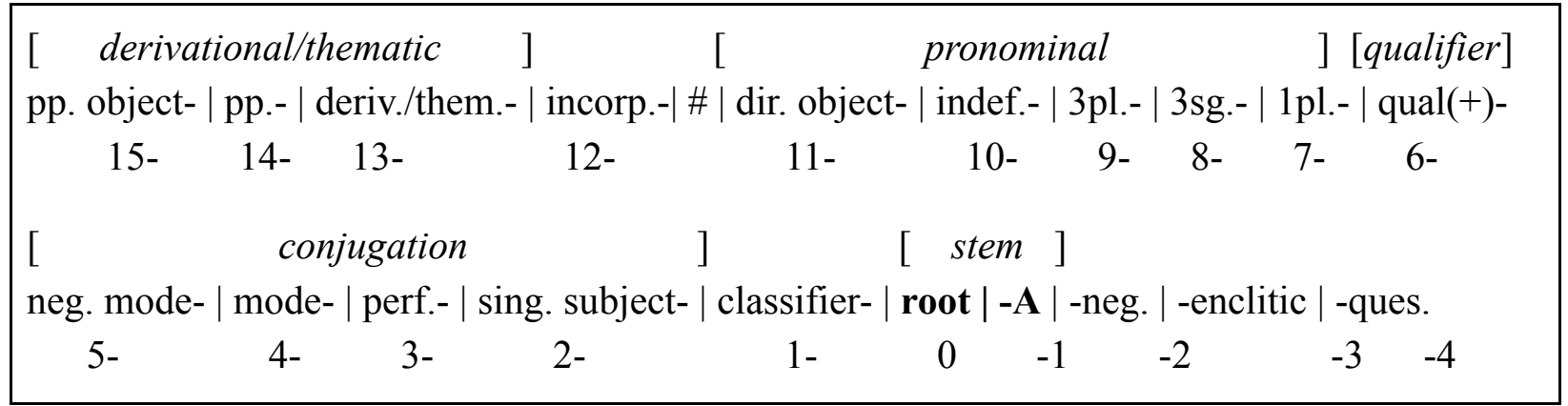

(adapted from Rice 1989, 2000, Axelrod 1993, and Jetté, Jones, and Kari 2000)

In this adapted template, each slot is labeled with respect to its grammatical function and numbered with respect to the stem in slot zero. To the immediate right of the stem is a suffix that indicates aspect, followed by a negation marker, then by an enclitic, such as a relativizer, and finally by a question marker. There are fifteen prefixes presented here, although a more accurate template would contain as many twenty-five prefix slots alone. These prefixes proceed outwards

\footnotetext{
${ }^{7}$ This template is a condensed version of the templates provided for Koyukon by Kari (2000) and Axelrod (1993), as well as those provided for the Slave language and the Athabaskan family as a whole by Rice (1989 and 2000, respectively).
} 
from the root, starting with classifiers, then followed by singular subjects, a perfective marker, a mode marker, a negative mode marker, qualifiers, first-person plural, third-person (singular object then plural), indefinite pronoun, and direct object.

These prefixes closest to the verb stem are said to be 'conjunct prefixes,' which are distinguished from the preceding prefixes, the 'disjunct prefixes,' on the basis of that some morpho-phonological processes affect the phonological shape of conjunct prefixes, but spare even phonologically identical disjunct prefixes. Many of these processes do not seem to cross a certain boundary, marked in this template with the pound symbol \#. The disjunct prefixes include, again proceeding away from the root, incorporate noun stems, derivational or thematic prefixes (more on derivation and thematic prefixes in section 3.2 and 4, respectively), and finally postpositions and their objects.

Also in the template, in brackets above the affixes, are boundaries of regions within the template in which contingent slots share a general function. These regions are called 'zones.' The slots responsible for marking subject and mode, for example, fall within the 'conjugation' zone. Likewise, slots that mark objects, as well as some plural subjects, fall within the 'pronominal' zone. The qualifiers, which have been collapsed in this truncated template, warrant their own zone, while those that attach the furthest away from the stem are called 'derivational' or 'thematic,' although this is not the only play where derivation or other thematically required elements find their place in the template.

It may be worth pointing out that the template above is posited on the basis primarily of distribution, rather than function. In a more accurate and elaborate template, as can be found in Kari (2000: 758) or Axelrod (1993: 15), there are a number of slots with only a single potential 
candidate, and therefore with only a single function. Other slots, on the other hand, can have tens of candidates with sometimes unrelated functions. Additionally, a single function, such as subject marking, may be relegated to two or more separate, potentially distant slots. It is therefore important to realize that a template merely captures the surface ordering of the morphs, and has no power to explain why they might be ordered that way. Such an enterprise falls within the purview of more theoretical discussions - namely word formation.

\subsection{Word formation}

General theories in linguistics that relate to word formation have yielded assumptions which are challenged by the surface structures of Athabaskan verbs. For example, the definitions of inflectional versus derivational categories partially rest on the tendencies for affixes considered to be derivational to attach closer to a word's stem than inflectional affixes. In a slightly different sense, derivation takes place 'first' in word formation, with inflection happening at a later stage of the process. This tendency seems to be violated by surface forms of verbs in Koyukon. Consider, for example, the following.

$$
\begin{aligned}
& \text { a. yenbełheenaadledaakk } \\
& \text { yen-bet-he- ne- le- le- daakk } \\
& \text { DS- T- 3PL.SUBJ- QUAL- } \mathrm{M}_{\mathrm{PRF}} \text { - CL- experience.MULT } \\
& \text { 'They (group of people) fell asleep' }
\end{aligned}
$$

In this verb, the verb theme meaning 'to fall asleep' is constituted by morphemes which are situated throughout the verb, from the thematic (T) prefix bet-in the second syllable of the word to the verb stem -daakk in the sixth and final syllable. Between bet-and-daakk, however, is the 
third-person plural (i.e., inflectional) prefix he(e)- in the third syllable, attaching closer to the root than the thematic (i.e., derivational) prefix. What's more, the derivational string (DS) prefix yen- is attached in the first syllable, the furthest away from the stem -daakk. These facts would seem to violate the distributional criteria for distinguishing between inflection and derivation, despite their respective functions being so prototypical for those separate categories (Axelrod, 1993; Rice, 2000).

Another theoretical conflict, although one that may not be clear until section 3.2., concerns a dynamic interdependence between multiple slots in the verb template. It has been theorized that processes of word formation attach affixes one at a time - that is, that a word's structure is binary-branching. The selection of any one affix in Koyukon, however, is often involved in a complex coordination between multiple slots which span the whole template. The verb theme, for instance, would need to be reconceptualized in order to accommodate this binary-based theory — a process which would likely bring the discussion of discerning lexicality in Koyukon verbs back to square one.

Saving most details for later sections, the verb above, which is by no measure an irregular one, also involves a system of interdependencies in which the the form of the stem is governed by the affix furthest away from it - as opposed to the other way around. The stem in turn simultaneously governs the form of the suffix as well as the modal and perfective prefixes, which appear on the other side of the inflectional subject slot from the stem. In short, the process of forming words in Koyukon, as is the case in any Athabaskan language, produces a morpheme 
order on the surface which is not isomorphic with the element-orderings most agreeable with general linguistic theory. ${ }^{8}$

In order both to capture the discernibility of multiple layers of morphology, as well as to accommodate the discontinuous nature of these layers, Kari (1992, as cited in Rice, 2000) offers an outline for the abstract process of word formation. This outline can be seen below.

Table 4. Word formation in Athabaskan, as proposed by Kari (1992).

\begin{tabular}{|c|c|c|c|c|c|c|c|c|}
\hline $\begin{array}{l}\text { Lexicon } \\
\text { (verb } \\
\text { theme) }\end{array}$ & $\rightarrow$ & $\begin{array}{c}((\text { Derivation })) \\
\text { asp. derivation } \\
\text { post-asp. } \\
\text { derivation } \\
\text { suerpasp. } \\
\text { derivation } \\
\text { non-asp. } \\
\text { derivation }\end{array}$ & $\rightarrow$ & $\begin{array}{c}\text { Base } \\
\text { (verb word } \\
\text { minus } \\
\text { inflection) }\end{array}$ & $\longrightarrow(($ inflection $))$ & $\begin{array}{c}\rightarrow \text { Underlying } \\
\text { form }\end{array}$ & $\begin{array}{c}\rightarrow((\text { Phono- } \\
\text { logical } \\
\text { rules }))\end{array}$ & $\rightarrow \begin{array}{c}\text { Surface } \\
\text { form }\end{array}$ \\
\hline
\end{tabular}

(adapted from Rice, 2000: 16)

This model conforms to widely espoused principles in word formation. The process begins in the lexicon (i.e., with a particular verb theme), then undergoes derivation to create a verb word which only contains those elements that either supply or modify the verbal meaning. This is then inflected for things like mode, subject, and object. This morphemically complete and unadulterated unit, the underlying form, then undergoes phonological rules which output the surface form which can be spoken.

An example is in order. Consider the following two derivatives of the theme bet\#ne+le+ten 'to fall asleep.' The first example does not take on any additional morphology via derivation, while the second one does.

\footnotetext{
${ }^{8}$ Although linguistic theory has changed over the last few years, Axelrod (1989) has written a succinct account of how Koyukon morphology violates the theory of binary branching.
} 
Table 5. Word formation exemplified with bel\#ne+le+ten 'to fall asleep'.

\begin{tabular}{|c|c|c|}
\hline \multirow[t]{4}{*}{ a. } & $\begin{array}{l}\text { Lexicon: } \\
\text { Base: }\end{array}$ & $\begin{array}{l}\text { bel\#ne+le+ten 'to fall asleep' } \\
\text { bel-ne-le-ten }\end{array}$ \\
\hline & Underlying form: & beł-ne-ne-ø-le-ten-n \\
\hline & Surface form: & betnaalten $h^{9}$ \\
\hline & & '(S)he fell asleep' \\
\hline \multirow[t]{5}{*}{ b. } & Lexicon: & bel\#ne+le+ten 'to fall asleep' \\
\hline & (Deriv. string: & yee\#k'e $+n e+D$ 'not be able to stop doing $\left.V^{\prime}\right)$ \\
\hline & Base: & yee-beł-k'e-ne-ne-d-le-ten \\
\hline & Underlying form: & yee-beł-k'e-ne-ne- $-\varnothing-d-l e-t e n-n$ \\
\hline & Surface form: & yeebetk'enaadletenh \\
\hline
\end{tabular}

'(S)he fell into a deep sleep, he was unable to wake up'

In $a$. above, the verb theme bel\#ne+le+ten first undergoes derivation -although with no effect - in order to create a base. That base then undergoes inflection to include the modal prefix $n e-$, the subject prefix $ø$-, and the perfective suffix $-n$. These undergo phonological processes to finally create the utterance betnaaltenh '(S)he fell asleep.' In $b$., the same verb theme accrues the derivational string yee\#k'e+ne+D 'not be able to stop doing $\mathrm{V}^{\prime}$ before creating a base that compresses these into a single string of interwoven prefixes and stem. This base undergoes inflection to take on the modal prefix $\varnothing^{-}$, the subject prefix $\varnothing^{-}$, and the perfective suffix $-n$. Finally, this long string of elements undergoes phonological processes to create the surface form yeebetk'enaadletenh '(S)he fell into a deep sleep.'

Schematics such as these are helpful in conceptualizing both the individual layers of Athabaskan verbal morphology as well as their interaction in the abstract. However, the simplicity of these models comes perhaps at the cost of explanatory power in why the product of

\footnotetext{
${ }^{9}$ A word-final consonant-devoicing rule devoices $-n$ to create the voiceless nasal $-n h$.
} 
this process is then ordered in the manner captured by the verb template. Rather than exploring the reasons for ordering constituents in the way they ultimately appear any further, ${ }^{10}$ what has been said so far may suffice to introduce a more in-depth analysis of the morphological elements that make up verbs in Koyukon.

\section{Parts of the verb}

With a general sense of how the verb functions as a whole, and how those functions may be schematized, a characterization of the verb would benefit from a more in-depth analysis of the verb's many constituents. This section is devoted to more accurately characterizing and exemplifying the Koyukon verb, beginning with the verb theme and its parts, as well as how that verb theme may then be 'fleshed out' with inflectional categories such as subject and mode. This section concludes with a very short elaboration on how inflected verbs may be further complexified through additional derivational elements.

\subsection{The verb theme}

What may be considered the most basic verbal unit in Koyukon is not just the verb stem, but rather the verb stem in combination with a small number of other affixual elements that are present in every inflectional and derivational modification of a given verb. This multi-parted element is called the 'verb theme.' The verb theme is, in other words, a skeletal structure of prefixes and verb stem which only together denote a particular verbal meaning. Consider the following examples.

\footnotetext{
${ }^{10}$ See Rice (2000) for a comprehensive and hopeful discussion on the matter of understanding Athabaskan word formation.
} 
a. yengheeł'aan'

$y e-\quad n(e)-g h e e^{11}-\varnothing-\quad t-\quad$ 'aan -'

3SG.OBJ- QUAL- $\mathrm{M}_{\mathrm{PRF}}-3$ SG.SUBJ- $\mathrm{CL}_{1}-$ see.MOM -PRF

'(S)he saw it, him'

b. huneeł'aanh

hu- $\quad n e-\quad(n) e-\varnothing_{-} \quad t-$ 'aan $\quad-(n) h$

AREAL- QUAL- $\mathrm{M}_{\mathrm{IMPRF}^{-}}$3SG.SUBJ- $\mathrm{CL}_{\uparrow}-$ look.DUR -IMPRF

' $(\mathrm{S})$ he is looking at an area, looking around'

Notice that although both the object and modal distinctions differ between the two examples above (i.e., $y e$ - versus $h t$-, perfective (PRF) versus imperfective (IMPRF)), they both contain the stem -'aan with the $t$ - classifier $^{12}$ to the immediate left of the stem, preceded by a null third-person singular subject prefix $\varnothing$-, then by the qualifier $n e-$, and finally by what functions more or less as the object $(\mathrm{O})$ of the seeing action. All of these, apart from the subject prefix, which is inflectional, constitute the verb theme meaning 'to see, look at O'. This theme (i.e., the appropriate stem set of 'aan, the $t$ - classifier, the $n e$ - qualifier, and an object) can be written as such: $\mathrm{O}+$ ne+1+'aan 'look at, see, observe O' (Jetté et al., 2000: 21).

The verb theme exemplified in example (5) above can be contrasted against other verb themes that also make use of the same verb stem -aan, although differ in the sorts of qualifiers and/or other thematic prefixes ( $\mathrm{T})$ which are required, as well as the valency (i.e., presence or absence of a direct object) of the verb.

\footnotetext{
${ }^{11}$ Here, the perfective mode prefix ghe- has assimilated an irregular prefix $e(e)$ - to produce the surface form ghee(Jetté et al., 2000: 21).

${ }^{12}$ For more on the form and function of classifiers and qualifiers, see section 3.1.2 and 3.1.3, respectively.
} 
(6)

a. seneeł'aanh

se- $\quad n e-\quad(n) e-\quad \varnothing-\quad t-\quad$ 'aan $\quad-(n) h$

1SG.OBJ- QUAL- $\mathrm{M}_{\mathrm{IMPRF}}-1 \mathrm{SG} . \mathrm{SUBJ}-\mathrm{CL}_{\mathrm{f}}-$ look.DUR -IMPRF

' $(\mathrm{S})$ he is looking at me' (theme: $\mathrm{O}+$ ne $+1+$ 'aan 'look at, see, observe $\mathrm{O}$ ')

b. sooł'aanh

$s(e)-\quad$ oo- $\quad \varnothing_{-} \quad \varnothing_{-} \quad t-\quad$ 'aan $\quad-(n) h$

1SG.OBJ- QUAL- $\mathrm{M}_{\mathrm{IMPRF}}$ - 3SG.SUBJ- $\mathrm{CL}_{\mathrm{r}}$ - look.DUR -IMPRF

'(S)he is waiting for me to act' (theme: $\mathrm{O}+\mathrm{oo}+1+$ 'aan 'wait for $\mathrm{O}$ to act')

c. dehut'aanh

de- $h u-\quad \varnothing-\quad \varnothing-\quad l-\quad$ 'aan $\quad-(n) h$

T- AREAL- $\mathrm{M}_{\mathrm{IMPRF}}-3 \mathrm{SG} . \mathrm{SUBJ}-\mathrm{CL}_{\uparrow}$ - look.DUR -IMPRF

'(S)he uses an area' (theme: de\# ${ }^{13} \mathrm{O}+1+$ 'aan 'gather, collect, use, do $\mathrm{O}^{\prime}$ )

d. yeghok'eghee'ann'

ye- gho- k'e- ghe- (n)e-'ann -'

(3SG.OBJ- PP $\left.{ }^{14}-\right)_{\mathrm{T}}$ QUAL- $\mathrm{M}_{\mathrm{PRF}}$ - PRF- look.DUR -PRF

'(S)he praised him, her' (theme: $\mathrm{O}+$ gho\#k'e+Ø+'aan 'praise O')

As these examples make clear, the exact semantic content of the modifications that the qualifier(s) and thematic prefix(es) make to the verb stem are not transparent. It is for this reason that these components are considered along with the verb stem to constitute a single unit in the Koyukon lexicon (Rice, 1989: p. 797; Axelrod, 1993: 17).

The practicality of positing a multi-parted minimal unit is most apparent when considering complex verbs which have an ultimate meaning that is seemingly unrelatable to themes with the same stem, as in the following examples.

\footnotetext{
${ }^{13}$ The pound symbol \# is used to represent the disjunct boundary in the verb template, over which certain phonological processes do not apply. This symbol otherwise has the same basic function as the plus symbol + in the conventions for composing verb themes.

${ }^{14} \mathrm{PP}=$ Postpositional object.
} 

a. $\mathrm{O}+1+$ dek
'shoot O with arrow'
$\mathrm{O}+\mathrm{de}+\mathrm{ne}+\mathrm{l}+\mathrm{dek}$
'write $\mathrm{O}$ '
b. $\mathrm{O}+\mathrm{G}+\mathrm{ne}+\mathrm{l}+$ yo
$\mathrm{P}+\mathrm{e} \# \mathrm{ht}+\mathrm{l}+$ yo
'raise, grow O'
'punish P'
c. $\mathrm{O}+\mathrm{G}+1+$ tsee
de + e \# oo + le + tsee
'plain, whittle, carve O'
'become established, acquire a habit'

Regardless of the psychological feasibility of the verb theme or the historical origins of the various components which constitute it, the verb theme is ultimately a practical theory which enables one to accommodate more easily the complex nature of the relationship between composite form and meaning in Athabaskan languages. Although analysis of Koyukon lexis stops at the verb theme, analysis of Koyukon's verbal grammar requires its dissection in order to investigate how it may serve its function as the foundation for meaning-making in verbs.

\subsubsection{Stems}

The right-most constituent of the verb theme is the verb stem. In Koyukon, verb stems are formed by marking a verb root, most of which have one syllable, for mode and aspect. This process can involve multiple kinds of changes, the most straightforward of which is suffixing a single consonant that marks either perfective, imperfective, or progressive. In many cases, lengthening or changing the root's vowel (i.e., ablaut) also occurs.

$$
\begin{aligned}
& \text { a. yengheet'aan' } \\
& \text { ye- } n(e)-g h e e^{15}-t-\text { 'aan -' } \\
& \text { 3SG.OBJ- QUAL- } \mathrm{M}_{\mathrm{PRF}^{-}} \mathrm{CL}_{1} \text { - see.DUR-PRF }
\end{aligned}
$$

'(S)he saw it, him'

\footnotetext{
${ }^{15}$ Here again, the perfective mode prefix ghe- has assimilated an irregular prefix $e(e)$ - to produce the surface form ghee-.
} 
b. k'ehunoł'eeł

$k^{\prime} e^{-} \quad h t-\quad n(e)-(g h e)^{16}-\quad t-\quad e e \quad-t$

INDEF.OBJ- AREAL- QUAL- $\mathrm{M}_{\mathrm{IMPRF} . \mathrm{PROG}}-\mathrm{CL}_{\mathrm{r}}-$ see.MOM.IMPRF-PROG

'(S)he is looking at something, some place'

The two verbs above make use of the same verb theme, $\mathrm{O}+$ ne $+1+$ 'aan 'to look at, to see', with the same root 'aan. However, the verb in $a$. makes use of the glottal stop -' perfective suffix and no changes to the root itself, while the verb in $b$. takes the progressive suffix $-t$ in addition to undergoing both a vowel raising process (changing $a a$ to $e e$ ) as well as a syllable-final consonant (i.e., coda) change, deleting its final nasal sound $-n$. The syllables 'aan' and -'eet both denote an action of looking, but 'aan' indicates that the action lasted for a duration of time (i.e., 'durative' aspect) but is no longer on-going (i.e., perfective), while eet emphasizes the quality of being on-going (i.e., 'progressive aspect).

There are fifteen aspects in Koyukon and four modal distinctions. ${ }^{17}$ Each verb root has a number of potential stem forms that it may take, depending on the modal distinction that best suits the time frame of conversation, as well as the aspectual distinction most aptly emphasized. These categories are intersecting, allowing a stem to mark for both categories. A particular root may theoretically have as many as sixty stem sets. However, virtually no verbs are semantically eligible to mark for one of all fifteen aspects, and for many verbs, multiple modal-aspectual combinations have identical stems.

\footnotetext{
${ }^{16}$ Here, a morpho-phonological rule assimilates the progressive prefix ghe- into the preceding qualifier prefix neand backs the vowel $e$ to $o$, creating the surface form no-.

${ }^{17}$ A comprehensive account of each of these aspects can be found in Axelrod (1993). See List of abbreviations for a full list of these aspects.
} 
As for predicting the phonological shape of a stem for a particular aspect or mode, there are only a few patterns across stem sets that can reveal any general morpho-phonological rule for marking a particular aspectual and/or modal distinction. For example, although vowel raising is necessary to turn -'aan into the momentative (MOM) progressive -'eet, this does not carry over to other roots with a similar phonological shape.
a) yeetlaakk
$y(e)-\quad e e-\quad \varnothing-\quad \varnothing-\quad \varnothing_{-}$tlaakk
3SG.OBJ- QUAL- $\mathrm{M}_{\mathrm{PRF}}-3 \mathrm{SG} . \mathrm{SUBJ}-\mathrm{CL}_{\varnothing}$ - handle.mushy.O.MOM.PRF
'(S)he found it (mushy object)'
b) yotluhtl
$y(e)-\quad$ (ghe)- $\varnothing-\quad$ - $\quad$ tluhtl
3SG.OBJ- $\mathrm{M}_{\mathrm{PROG}}-3 \mathrm{SG} . \mathrm{SUBJ}-\mathrm{CL}_{\varnothing}$ - handle.mushy.O.PROG
'(S)he is carrying it (mushy object)'

Both 'aan in (8) and tlaakk above have a long low front vowel aa for the momentaneous perfective form, but while 'aan raises to 'eet in the progressive, tlaakk backs to tluhtl in the progressive. Vowel raising is therefore not a relevant process for forming the progressive stem in this case.

Other processes are better understood, although are no less complicated. One example, from Axelrod (1993), illustrates a series of phonological processes that are required to reconcile a violation of phonotactics in a root syllable that takes on the customary suffix $-k$.

$$
\text { daatl 'pl. go' }+-k \text { (cust.) } \rightarrow(1) \text { det }+-k \rightarrow \text { (2) dekt } \rightarrow \text { (3) deyht } \rightarrow \text { (4) deyhtl }
$$


This example, ultimately becoming deyhtl 'pl. customarily walk, go', exhibits a number of phonological processes that produce a phonotactically allowable stem that consists of the root daatl and the customary suffix consonant $-k$. Step (1) shows the selection of the proper base form of the verb. Step (2) shows that in the case of consonant clusters created by morphosyntactic constructions like this, 'lateral' segments (e.g., /1/, ///) must come last, causing the suffix $-k$ and the base-final lateral consonant to metathesize (i.e., switch positions) to allow the lateral segment to come last. Step (3) shows the continuation of the $/ k /$ to the voiceless $[y h]$ (i.e., the weakening of the closure necessary to articulate a ' $k$ ' sound). Finally, step (4) exhibits the affrication of / $/$ / to [tl] (i.e., the breaking up of the two contingent fricative sounds /yh/ and /t/ with a stop /yhtil/).

Phonological processes such as assimilation, deletion, and metathesis account for some stem formations, in some cases having the effect of phonologically 'grafting' an aspect-marking suffix onto the base to form a single, phonotactically allowable, morphologically intermingled stem. However, the composition of other stems, as well as the processes which produced their surface forms, is not as easily gleaned. For this reason, it can be easier to treat stems as a single unit which encodes (1) a verbal action, (2) a modal distinction, as well as (3) an aspectual designation, without analyzing them any further.

\subsubsection{Classifiers}

Moving leftwards from the verb stem, the next obligatory constituent of the verb theme is what is known as a 'classifier.' Verb classifiers are a peculiar and characteristic component of Athabaskan languages which have received much attention in Athabaskanist literature (Hoijer, 
1948; Krauss, 1969; Pinnow, 1970). This is in part because the semantic contribution that they bring to bear on the meaning of the verb root is not easily discernible, and their grammatical function also seems to span multiple traditional categories, including causativity, reflexivity, passivity, reciprocity, and, in intransitive verbs, repetition (Thompson, 1977: 20; Rice, 1989: 429). These functions, and the four classifiers of Koyukon that mark them, are detailed in this section.

The four classifiers in Koyukon are $\varnothing$-, $t-, D$ - (de-), and $l e$-. These may be grouped into two groups, $\varnothing$ - and $t$-, with a single process, known as the 'D-effect,' turning $\varnothing$ - into $d e$-, and $t$ into le-. The D-effect itself encodes reflexivity, passivity, intransitive-repetitive, and reciprocity, although before investigating the D-effect and its functions, consider the difference between the following verb themes that have either the classifier $\varnothing$ - or $t$ -

\subsubsection{Classifiers $\emptyset$ - and $t$ -}

Table 6. Verb themes with either Ø- or 1 -classifiers.

\begin{tabular}{|c|c|c|c|}
\hline $\begin{array}{l}\mathrm{G}^{18}+\varnothing+\mathrm{zoo} \\
\mathrm{k}^{\prime} \mathrm{e}+\mathrm{ne}+\varnothing+\text { to } \\
\mathrm{O}+\mathrm{G}+\varnothing+\text { 'otl } \\
\text { ghe+Ø+no } \\
\mathrm{O}+\mathrm{G}+\varnothing+\text { tl'ekk } \\
\varnothing+\text { yo }\end{array}$ & $\begin{array}{l}\text { 'be good, beautiful' } \\
\text { 'glance, gaze' } \\
\text { 'chew, bite O' } \\
\text { 'stir, budge' } \\
\text { 'smooth, comb O' } \\
\text { 'sg. go, walk' }\end{array}$ & $\begin{array}{l}\mathrm{O}+\mathrm{G}+1+\text { tsee } \\
\mathrm{O}+\mathrm{G}+1+\text { ghttl } \\
\mathrm{O}+\text { de }+1+\text { tlookk } \\
\mathrm{O}+\text { de }+ \text { ne }+1+\text { dek } \\
\mathrm{O}+\mathrm{G}+1+\text { 'o } \\
\mathrm{O}+\mathrm{G}+1+\text { baats }\end{array}$ & $\begin{array}{l}\text { 'make O' } \\
\text { 'drum on, pount O' } \\
\text { 'plug, fill in O' } \\
\text { 'draw, write O' } \\
\text { 'have, keep O in position' } \\
\text { 'cook O by boiling' }\end{array}$ \\
\hline
\end{tabular}

There are a number of things to note with these two groups of verb themes. First, notice that all of the verb themes with the $t$ - classifier have direct objects, while most, but not all of the verb themes with the $\varnothing$ - qualifier have direct objects. With this observation, although based on a

\footnotetext{
${ }^{18} \mathrm{G}=$ object gender, a pronominal prefix that labels the object as belonging to one of six categories of objects based on their physical qualities. See section 3.1.4.
} 
limited number of verb themes, it stands to reason that the presence or absence of the $t$ - qualifier implicates, though does not determine per se, whether a verb theme will contain a direct object or not. In other words, the classifier implicates the 'valency' (i.e., total number of arguments, including subject) or 'transitivity' (i.e., presence or absence of an object or objects) of the verb theme.

This assumption about the function of the $t$ - classifier holds feasible in that an intransitive verb theme may take on an additional argument (i.e., a direct object), but this must be accompanied by a switch from the $\varnothing$ - classifier to $t$-. In other words, the $t$ - classifier functions as a 'transitivizer,' allowing otherwise objectless verbs to be applied to objects.

a. naalyonh

$$
\begin{array}{lccccc}
\varnothing- & n e- & l(e)^{19}-\varnothing- & \varnothing- & y o & -n h \\
\mathrm{G}_{\text {human }}- & \text { QUAL- } & \mathrm{M}_{\mathrm{PRF}^{-}} & \text {3SG.SUBJ- } & \mathrm{CL}_{\varnothing}- & \text { grow.MOM }-\mathrm{PRF}
\end{array}
$$

'He grew' (theme: G+ne+Ø+yo 'grow')

b. yenaatlyonh

$y e-\quad \varnothing-\quad n e-\quad l(e)-\varnothing-\quad t^{20}-y o \quad-n h$

3SG.OBJ- $\mathrm{G}_{\text {human }}-$ QUAL- $\mathrm{M}_{\mathrm{PRF}}-3 \mathrm{SG} . \mathrm{SUBJ}-\mathrm{CL}_{\mathrm{f}}$ - grow.MOM -PRF

'(S)he raised him' (theme: $\mathrm{O}+\mathrm{G}+$ ne $+1+$ yo 'grow, raise $\mathrm{O}$ ')

In (11) above, the addition of the direct object $y e$ - in $b$. is accompanied by a change from the classifier $\varnothing$ - to the classifier $t$-, allowing the verb 'grow' to be applied to a direct object (i.e., 'grow, raise $\mathrm{O}^{\prime}$ ). This function is virtually identical to what might be called a 'causitivizer,' which also allows for introducing an additional object into the valency of a verb. In the case of

\footnotetext{
${ }^{19}$ Here, in accordance with a morpho-phonological rule, the vowel of the qualifier $n e$ - is said to 'expand' into naabefore the modal prefix le- (Thompson, 1977: 93).

${ }^{20}$ Here, modal le- + classifier $t-\rightarrow t l-$.
} 
causatives, the resulting change in meaning is that the subject is no longer the agent of the action denoted by the verb, but instead causes someone or something else to be the agent of the action. For example:

a. $\mathrm{k}^{\prime}$ ehonh

$k^{\prime} e-\quad \varnothing-\quad \varnothing-\quad \varnothing-\quad \varnothing-\quad h o n \quad-(n) h$

INDEF.OBJ- $\mathrm{G}_{\mathrm{INDEF}}-\mathrm{M}_{\mathrm{IMPRF}}-3 \mathrm{SG} . \mathrm{SUBJ}-\mathrm{CL}_{\varnothing}$ - eat.DUR -IMPRF

'(S)he is eating something' (theme: $\mathrm{O}+\mathrm{G}+\varnothing+$ hon 'eat $\mathrm{O}$ ')

b. yek'ełonh

$y e-\quad(e)-k^{\prime} e-\quad \varnothing-\quad \varnothing-\quad \varnothing-\quad l-\quad(h)$ on $\quad-(n) h$

3SG.OBJ- PP- INDEF.OBJ- $\mathrm{G}_{\mathrm{INDEF}}-\mathrm{M}_{\mathrm{IMPRF}}-3 \mathrm{SG} . \mathrm{SUBJ}-\mathrm{CL}_{\mathrm{f}}$ - eat.DUR -IMPRF

'(S)he is feeding something to him, her' (theme: $\mathrm{P}^{21}+\mathrm{e} \# \mathrm{O}+\mathrm{G}+1+$ hon 'feed $\mathrm{P}$ to $\mathrm{O}$ ')

In $b$. above, the postpositional phrase ye-e\#, combined with the classifier $t$-, turns a monotransitive verb (i.e., a verb with one direct object, in this case $k^{\prime} e$-) into a ditransitive verb with the indirect object ye-. The causative modification can be thought of here as a morpho-syntactic change from a verb meaning 'eat $\mathrm{O}$ ' to a verb meaning 'cause $\mathrm{P}$ to eat $\mathrm{O}$.'

\subsubsection{D-effect: Classifiers $D$ - (de-) and $l e$ -}

The remaining two classifiers, $d e$ - and $l e$-, each play one of a number of potential grammatical and semantic functions, including passivity (i.e., the grammatico-semantic foregrounding of the object or, conversely, the omission of the agentive subject), reflexivity (i.e., the degree to which the action affects the subject), repetition in intransitive verbs (i.e., the recurrence or repetition of an action which does not affect a direct object), or reciprocity (i.e., the

\footnotetext{
${ }^{21} \mathrm{P}=$ Object of a postposition, functioning here as the indirect object of the verb.
} 
mutual benefit or affect of an action between arguments). The addition of any of these meanings to a verb is indexed in the changing of either $\varnothing$ - to $d e$-, or $t$ - to $l e-$, which retain their respective meanings described above. This process is known in Athabaskanist literature as the 'D-effect'22 (Rice, 1989; Thompson, 1977, 1996; Krauss, 1969).

Consider the ability of the D-effect rule to produce the passive voice in the following examples.

a. yeghonh

ye- $\varnothing-\quad \varnothing-\quad \varnothing-\quad$ ghon $\quad-(n) h$

3.OBJ- $\mathrm{M}_{\mathrm{IMPRF}}-3 \mathrm{SG} . \mathrm{SUBJ}-\mathrm{CL}_{\varnothing}-$ make.pl.O.DUR-IMPRF

'(S)he is making them'

b. deghonh

ø- $\quad$ - $\quad$ de- ghon $\quad-(n) h$

$\mathrm{M}_{\mathrm{IMPRF}}-$ 3.SUBJ- $\mathrm{CL}_{\varnothing+\mathrm{D}^{-}}$- make.pl.O.DUR-IMPRF

'They are being made'

The process of turning the active verb in $a$. into the passive form in $b$. involves the reverse of the process to form the causative by adding an argument. In $a$, , the agent of the action (i.e., (s)he, the maker) fills the morpho-syntactic role of subject. This agent, however, is omitted in $b$, allowing the object in $a$. (i.e., the things being made) to fulfil the subject role in $b$. This change in valency is indexed by a change in classifier from $\varnothing$ - in the theme $\mathrm{O}+\mathrm{G}+\emptyset+$ ghon 'make pl. O' to the passive form de- in deghonh. The same process can be seen with a verb theme that originally contains a $t$ - classifier.

\footnotetext{
${ }^{22}$ The D-effect gets its name from a reconstructed morpheme that existed in Proto-Athabaskan, although which has since shifted out of its original morpho-phonemic milieu, leaving only the trace effect discernible in the contemporary morpho-phonological behavior of classifiers.
} 
(14)

a. etlbaats

$\varnothing-\quad e(s)^{23}-\quad t-$ baats $\quad \varnothing$

$\mathrm{M}_{\mathrm{IMPRF}}-1 \mathrm{SG} . \mathrm{SUBJ}-\mathrm{CL}_{1}-$ boil.DUR -IMPRF

'I am boiling it'

b. lebaats

ø- $\varnothing-\quad$ le- baats $\varnothing$

$\mathrm{M}_{\mathrm{IMPRF}}-1 \mathrm{SG} . \mathrm{SUBJ}-\mathrm{CL}_{1+\mathrm{D}}$ - boil.DUR -IMPRF

'It is being boiled'

Here again, the D-effect has applied to (1) change the classifier from $t$ - to le-, (2) remove the agentive subject, and (3) 'promote' the once-object to now-subject to form the passive voice.

The next function which the D-effect may accompany is the reflexive voice, basically meaning that the verbal action affects primarily the agentive subject. See, for example, the following example.

a. yenk'edeghee'onh

ye- $n(e)-k^{\prime} e-\quad$ de- ghee- $\varnothing-\quad \varnothing-\quad{ }^{\prime} o \quad-n h$

3SG- T- INDEF.OBJ- QUAL- $\mathrm{M}_{\mathrm{PRF}}-3 \mathrm{SG} . \mathrm{SUBJ}-\mathrm{CL}_{\emptyset}$ - handle.compact.O.MOM-PRF

'(S)he put something (a hat) on him, her'

b. nek'edot'onh

$n e-k^{\prime} e-\quad d(e)^{24}-g h e-\varnothing-\quad d e-{ }^{\prime} o \quad-n h$

T- INDEF.OBJ- QUAL- $\mathrm{M}_{\mathrm{PRF}}-3 \mathrm{SG} . \mathrm{SUBJ}-\mathrm{CL}_{\emptyset+\mathrm{D}}$ - handle.compact.O.MOM-PRF

'(S)he put something (a hat) on (his-/herself)'

In $b$. above, the reflexive action of putting a hat on oneself requires the use of the reflexive (i.e., D-affected classifier) $d e$-, when an action might otherwise call for a $\varnothing$-classifier. Likewise, if an action affects primarily the subject, then themes otherwise requiring a $t$-classifier will also take

\footnotetext{
${ }^{23}$ Here again, the first-person singular subject es- + classifier $t-\rightarrow$ etl.

${ }^{24}$ Here, as before, the modal prefix ghe- is back-assimilated into the preceding prefix de-, producing the surface form $d o-$.
} 
the D-effect form le-, sometimes additionally taking on the derivational string (DS) of prefixes $h o+d e(+\mathrm{D}-\mathrm{effect})$ that together emphasize this reflexive meaning.

a. yeneeł'aanh

$y e-\quad n e-\quad(n) e-\quad \varnothing-\quad t-\quad$ 'aan $\quad-(n) h$

1SG.OBJ- QUAL- $\mathrm{M}_{\mathrm{IMPRF}}-1 \mathrm{SG} . \mathrm{SUBJ}-\mathrm{CL}_{\mathrm{f}}$ - look.DUR -IMPRF

'(S)he is looking at it'

b. hodenle'aanh

ho- de- $\quad n(e)-\quad \varnothing-\quad \varnothing-\quad l e-\quad$ 'aan $\quad-(n) h$

(DS- DS- $)_{\text {REFL }}$ QUAL- $\mathrm{M}_{\mathrm{IMPRF}}-1 \mathrm{SG} . \mathrm{SUBJ}-\mathrm{CL}_{1+\mathrm{D}}$ - look.DUR -IMPRF

'(S)he is looking at herself'

The next function that the D-effect on classifiers may have is that of communicating the repetitive or recurring nature of an action that does not involve any direct object. This process, which usually involves the prefix no- is termed the 'intransitive-reduplicative' (Thompson, 1977) or the 'iterative' (Jetté et al., 2000). Consider the following.

a. yeetltseenh

ye- (le)- $\varnothing-\quad t-$ tsee $\quad-n h$

3SG.OBJ- $\mathrm{M}_{\mathrm{PRF}}-3 \mathrm{SG} . \mathrm{SUBJ}-\mathrm{CL}_{\uparrow}-$ make.sg.O.CONC -PRF

'(S)he made it'

b. noyeetltseenh

no- $y e-\quad(l e)-\varnothing-\quad t-$ tsee $\quad-n h$

ITER.- 3SG.OBJ- $\mathrm{M}_{\mathrm{PRF}}$ - 3SG.SUBJ- $\mathrm{CL}_{\mathfrak{f}}-$ make.sg.O.CONC -PRF

'(S)he repaired it, made it over'

The next and final structure that the D-effect accompanies denotes a reciprocal effect (i.e., between two separate entities). Consider the following example. 
a. yootunh

$y(e)-\quad$ oo- $\quad \varnothing-\quad \varnothing-\quad \varnothing_{-}$tun $\quad-(n) h$

3SG.OBJ- QUAL- $\mathrm{M}_{\mathrm{IMPRF}}-3 \mathrm{SG} . \mathrm{SUBJ}-\mathrm{CL}_{\varnothing}$ - hold.DUR -IMPRF

'He is holding onto it'

b. neełts'oodetunh

neet- $t s^{\prime}(e)-\quad$ oo- $\varnothing-\quad d e-\quad$ tun $\quad-(n) h$

RECIP- 1PL.SUBJ- QUAL- $\mathrm{M}_{\mathrm{IMPRF}}-\mathrm{CL}_{\emptyset+\mathrm{D}^{-}}$hold.DUR -IMPRF

'We are holding each other' (457)

The reciprocal is formed in $b$, though not in $a$., by the reciprocal prefix neet-, meaning basically 'each other,' as well as the D-effect on the $\varnothing$ - classifier of the theme $\mathrm{O}+\mathrm{oo}+\mathrm{G}+\varnothing+$ tun 'hold $\mathrm{O}$ ' to form the classifier $d e-$.

The many examples above illustrate that a classifier, the selection of which being thematic (i.e., required by a particular verb theme), undergoes a predictable change to index and accompany a grammatical change in the verb as a whole. The classifier itself then, it stands to reason, would be more aptly held accountable for contributing grammatical, as opposed to semantic, information. While this treatment of classifiers seems to be appropriate for modern-day Athabaskan languages, Jetté (1906, as cited in Jetté et al., 2000: 2) hypothesizes that these classifiers did at one time serve primarily the meaning of a verb, rather than its rote grammar. To illustrate how classifiers might at one time have been productively used more or less at the will of the speaker to imbue an utterance with a certain nuance of meaning, Jetté offers the following examples using the verb stem $d o$, appearing most often in the verb theme $\varnothing+$ do 'sg. sits, stays, dwells'. Consider the change in classifier between them, and their respective meanings. 
19) a. setoye' ghu lesdo

se- toy $\quad e^{\prime} \quad$ ght le- $\quad(e) s-\quad$ o- $d o \quad$ -

1SG.POSS- uncle -POSS with $\mathrm{M}_{\mathrm{IMPRF}}-1$ SG.SUBJ- $\mathbf{C L}_{\boldsymbol{\emptyset}^{-}}$dwell.NEU -IMPRF

'I live with my uncle'

b. yoodo' hut'aane ghu lesedo

yoodo' hut'aane ghule- $\quad(e) s^{-} \quad(d) e-d o \quad-\varnothing$

far.downstream inhabitants with $\mathrm{M}_{\mathrm{IMPRF}}-1 \mathrm{SG}$.SUBJ- $\mathbf{C L}_{\boldsymbol{\emptyset}+\mathbf{D}}-$ dwell.NEU -IMPRF

'I cohabit with one of the lower tribe (viz. I have a wife of the lower tribe)'

c. sedenaa' mugh letldo

se- denaa - $(e)^{\prime} \quad m(e)-u g h l e-\quad(e s)^{25}-\quad \boldsymbol{t}$ do $\quad$ -

1SG.POSS- child -POSS 3SG- by $\mathrm{M}_{\mathrm{IMPRF}^{-}}$1SG.SUBJ- CL $\mathbf{L}_{\mathbf{1}}-\mathrm{dwell}$.NEU -IMPRF

'I keep my child with him, in his care'

d. medenaa' ghu legedo

me- denaa-(e)' ghule- $\quad(e)^{26} s^{\prime} \quad$ (l)e- do $\quad$-ø

3SG.POSS- child -POSS with $\mathrm{M}_{\mathrm{IMPRF}}{ }^{-1 S G . S U B J-} \mathbf{C L}_{\mathbf{l + D}}-$ dwell.NEU -IMPRF

'I keep his child with me (viz. as a servant)'

The last two examples are causative with the meaning 'I keep...' (i.e., 'I cause his child to dwell'), and therefore require the classifier $t$-. Notice that examples $b$. and $d$. have both undergone D-effect, and that, as a result, they both have connotations of self-advantage that their respective unaffected versions lack. The example in $b$. connotes that the speaker gets something out of cohabiting with 'one of the lower tribe' — namely marriage — while $d$. connotes that the speaker benefits from having 'his child' stay with the speaker — namely, a servant. The choice of classifier in this example may give evidence of a historically more prolific use of classifiers that was more semantic in nature. This use, however, seems to have been ossified into the lexis of the language, leaving classifiers with a more strictly thematic and grammatical role.

\footnotetext{
${ }^{25}$ Here, first-person singular subject es- + classifier $t-\rightarrow t l-$.

${ }^{26}$ Here, first-person singular subject $e s-+$ the d-affected $t$ - classifier $l e-\rightarrow$ ege-.
} 


\subsubsection{Qualifiers}

The next required component in some verb themes are the so-called 'qualifiers.' The function of these components are more lexical than grammatical, and therefore require less explanation than classifiers. That said, qualifiers play an even more peculiar role in the verb than classifiers, and discussions within Athabaskanist literature on this topic have been less conclusive on how they might be more satisfyingly schematized, or where they have their origins (Krauss, 1969; Hargus, 2000; Kari, 1989). Like classifiers, it is likely that the function of qualifiers was at one time more productive and transparent, although has been obscured over time as a result of the routine and later ossified combination of certain elements. The product of this diachronic process of lexicalization has been the verb theme, in which the whole verbal meaning is now difficult to analyze into parts and ascribe to its various constituents, such as qualifiers. In other words, the contemporary use of any qualifier, as Athabaskanist theory would have it, is primarily required by a particular verb theme, as opposed to being chosen on the basis of its individual function.

Although qualifiers' role is primarily thematic, their semantics can be gleaned at least partially through a comparison of themes that require them. Consider the following themes, all of which contain the qualifier $o o-$.

(20) a. yootunh

$y(e)-\quad$ oo- $\quad \varnothing-\quad \varnothing-\quad$ ø- tun $\quad-(n) h$

3SG.OBJ- QUAL- $\mathrm{M}_{\mathrm{IMPRF}}-3 \mathrm{SG} . \mathrm{SUBJ}-\mathrm{CL}_{\varnothing}$ - hold.DUR -IMPRF

'He is holding onto it' (theme: $\mathrm{O}+\mathrm{oo}+\mathrm{G}+\varnothing+$ tun 'hold, grip $\mathrm{O}^{\prime}$ ) 
b. sooł'aanh

$s(e)-\quad o o-\quad \varnothing-\quad \varnothing-\quad t-\quad$ 'aan $\quad-(n) h$

1SG.OBJ- QUAL- $\mathrm{M}_{\mathrm{IMPRF}}$ - $3 \mathrm{SG}$.SUBJ- $\mathrm{CL}_{\mathrm{f}}$ - look.DUR -IMPRF

' $(\mathrm{S})$ he is waiting for me to act' (theme: $\mathrm{O}+\mathrm{oo}+1+$ 'aan 'wait for $\mathrm{O}$ to act')

c. yoolaatltl'onh

$y(e)-\quad$ oo- $\quad l(e)-\quad(l e)^{27}-\quad \varnothing-\quad t-\quad t l^{\prime}$ on $\quad-(n) h$

3SG.OBJ- QUAL- QUAL- $\mathrm{M}_{\mathrm{IMPRF}}$ - $3 \mathrm{SG}$.SUBJ- $\mathrm{CL}_{\mathrm{f}}$ - hear.NEU -IMPRF

'(S)he understands, listens to him, her'

The examples above all share in common the semantic thread of intentionality on the part of the speaker. As Jetté (1906, as cited in Jetté et al., 2000: 12) writes, "[prefix oo-] occurs in most verbs implying an act of the mind, a purpose or an effort, a design." With respect to this described function, the prefix $o o$ - is termed in the Koyukon Athabaskan Dictionary (ibid) as the 'conative' qualifier prefix.

The classification of qualifiers is complicated by the fact that other prefixes that occupy the same zone of the verb template have a wide range of functions, some of which are less transparent, if discernible at all. The qualifier ghe- is one such prefix which occurs in various seemingly unrelated themes.

a. ts'eghono

$t^{\prime} e-\quad g h(e)-(g h e)-\varnothing-\quad$ no $\quad-\varnothing$

1PL.SUBJ- QUAL- $\mathrm{M}_{\mathrm{IMPRF}}-\mathrm{CL}_{\varnothing}$ - be.alive.NEU -IMPRF

'We are alive' (theme: ghe $+\varnothing+$ no 'be alive, move, twitch')

b. ghaalneek

$g h(e)-l(e)-\varnothing-\quad \quad \varnothing-\quad$ neek $\quad-\varnothing$
QUAL- $\mathrm{M}_{\mathrm{PRF}}-$ 3SG.SUBJ- $\mathrm{CL}_{\varnothing}$ - move.hand.PRF -CONC

'It (valuable) is stored' (theme: ghe $+\mathrm{G}+\emptyset+$ neek 'valuable object is in position'

\footnotetext{
${ }^{27}$ Per two separate morpho-phonological rules, the modal prefix le- (1) triggers the 'expansion' of the preceding lequalifier's vowel to $a a$ and (2) combines with the classifier $t$ - to form $t l$ - (Thompson, 1977: 77, 93).
} 
In addition to their sometimes opaque distribution, some qualifiers are only found in a small number of verb themes. The qualifier $h u$-, for example, only appears in the irregular verb theme he + ne $+\varnothing+$ yo 'sg. talks', as in:

$$
\begin{aligned}
& \text { a. hensaayh } \\
& h e-\quad n(e)-\quad \varnothing-\quad(e) s-\quad \varnothing-\quad(y) a a \quad-y h \\
& \text { QUAL- QUAL- } \mathrm{M}_{\mathrm{IMPRF}}-1 \text { SG.SUBJ- } \mathrm{CL}_{\emptyset} \text { - talk.DUR -IMPRF } \\
& \text { 'I am talking' }
\end{aligned}
$$

Like $h e-$, the qualifier $l e$ - is also rare, occurring in only a small handful of seemingly unrelated themes in Koyukon.

(23) a. yoolaatlt'onh

$y(e)-\quad$ oo- $\quad l(e)-\quad(l e)-\quad \varnothing-\quad t-\quad t l^{\prime} o n \quad-(n) h$

3SG.OBJ- QUAL- QUAL- $\mathrm{M}_{\mathrm{IMPRF}}$ - $3 \mathrm{SG} . \mathrm{SUBJ}-\mathrm{CL}_{4}$ - hear.NEU -IMPRF

'(S)he understands, listens to him, her' (theme: $\mathrm{O}+\mathrm{oo}+\mathrm{le}+\mathrm{Y}+\mathrm{tl}$ 'on 'listen to $\mathrm{O}$ ')

b. yelaatlghaanh

$$
\text { ye- } \quad l(e)-(l e)-\varnothing-\quad t-\quad \text { gha }-n h
$$

3SG.OBJ- QUAL- $\mathrm{M}_{\mathrm{PRF}}$ - 3SG.SUBJ- $\mathrm{CL}_{-}$- kill.sg.CONC -PRF

'(S)he killed it, him' (theme: $\mathrm{O}+\mathrm{G}+\mathrm{le}+\mathrm{l}+$ ghaa 'kill, injure sg. person, dog') 
With such few examples of the qualifiers $h e$ - and $l e$ - in the language, a reconstruction of their historical semantics is not possible. Despite this, their usage in the context of their respective few themes is obligatory, underscoring their purely lexical signification.

In contrast to ghe-, he-, and le-, the function of the qualifier te- is so transparent and grammatical that it would seem to serve as an interruption to the zone of qualifiers as a whole (Kari, 1989: 433; Hargus, 2000).

a. k'ehonh

$k^{\prime} e^{-} \quad \varnothing-\quad \varnothing-\quad \emptyset_{-} \quad$ hon $\quad-(n) h$

INDEF.OBJ- $\mathrm{M}_{\mathrm{IMPRF}^{-}}$3SG.SUBJ- $\mathrm{CL}_{\emptyset^{-}}$eat.DUR -IMPRF

'(S)he is eating something'

b. k'etaalhon'

$k^{\prime} e-\quad t(e)-l(e)-\varnothing-\quad \varnothing-\quad h o n \quad-'$

INDEF.OBJ- QUAL- $\mathrm{M}_{\mathrm{PRF}}{ }^{-}$3SG.SUBJ- $\mathrm{CL}_{\emptyset^{-}}$eat.DUR -PRF

'(S)he started to eat something'

The addition of the qualifier te- denotes the starting of an action, rather than the 'doing' of the action itself. For this reason, the qualifier te- is termed in the Koyukon Athabaskan Dictionary (Jetté et al., 2000: 504) the 'inceptive' prefix. Its function is also employed alongside the ghemodal prefix to mark the future tense.

a. gheskkaał

ghe- $(e) s-\quad$ o- $k k a a \quad-t$

$\mathrm{M}_{\mathrm{IMPRF}}{ }^{-1 S G . S U B J}-\mathrm{CL}_{\emptyset^{-}}$- paddle.DUR -IMPRF

'I am going by boat'

b. taagheskkaał

t(e)- ghe- $(e)_{s-} \quad$ ø- $k k a a \quad-t$

$\mathrm{QUAL}_{\mathrm{INCEP}}-\mathrm{M}_{\mathrm{IMPRF}}-1 \mathrm{SG} . \mathrm{SUBJ}-\mathrm{CL}_{\varnothing}$ - paddle.DUR -IMPRF

'I will go by boat' 
Being so transparent in its purely grammatical function, the inceptive te- qualifier stands in stark contrast to the other affixes with which it shares its position in the verbal template.

\subsubsection{Gender qualifiers}

Other qualifiers, such as $d e-$, $n e-$, and $h t t$, are abundant in verbs themes across the language, and their meaning is therefore easier to ascertain. Although they do occur in some unrelated themes in which their meaning can be difficult to determine, the qualifiers, de-, ne-, and $h t$ - also serve a separate function which is quite different from other qualifiers. Rather than contributing semantics to the action denoted by the theme as a whole, these qualifiers, which may be termed 'gender qualifiers' (glossed earlier as G) denote the physical qualities of the subject or object (Krauss, 1968). Consider the following verbs with the de-, ne- and httqualifiers.

a. daaltonh

$$
\text { de- } l(e)-\quad \varnothing-\quad \varnothing-\quad \text { ton } \quad-(n) h
$$

$\mathrm{G}_{\text {plant }}-\mathrm{M}_{\mathrm{IMPRF}}-$ 3SG.SUBJ- $\mathrm{CL}_{\emptyset^{-}}$long.O.is.in.position.NEU -IMPRF

'It (stick) is there, is in position'

b. denaal'onh

$d e-(n) e-l(e)-\quad \varnothing-\quad \varnothing-\quad ' o \quad-n h$

(G- G- $)_{\text {rock }}-\mathrm{M}_{\mathrm{IMPRF}}-3 \mathrm{SG}$.SUBJ- $\mathrm{CL}_{\emptyset^{-}}$- compact.O.is.in.position.NEU -IMPRF

'It (a rock) is there, is in position;

c. hunetl'aanh

$h t^{-} \quad n e-\quad \emptyset_{-} \quad(e s)-\quad(t)-{ }^{\prime} a a n \quad-(n) h$

$\mathrm{G}_{\text {area, abstract }}{ }^{-} \mathrm{QUAL}^{28}-\mathrm{M}_{\mathrm{IMPRF}}-1 \mathrm{SG} . \mathrm{SUBJ}-\mathrm{CL}_{1}$ - see.MOM -IMPRF

'I see it (area, abstract $\mathrm{O}$ )

\footnotetext{
${ }^{28}$ This is one example of a verb theme where the meaning of the qualifier $n e$ - is more lexical (i.e., functionally opaque) than the gender qualifier $h t-$, despite both being required by the theme.
} 
In these verbs above, the physical qualities of the subject of intransitive verbs (e.g., those meaning 'It is there, in position') or the object of transitive verbs (e.g., 'I see it') is denoted at least in part by the gender prefix in the qualifier slot of the verb. There are four ${ }^{29}$ phonologically distinct gender markers in Koyukon and two combinatory genders (Thompson, 1993), each marking a number of different classes of nominal entities.

Table 7. The six genders of Koyukon and their qualifier prefixes/noun class markers.

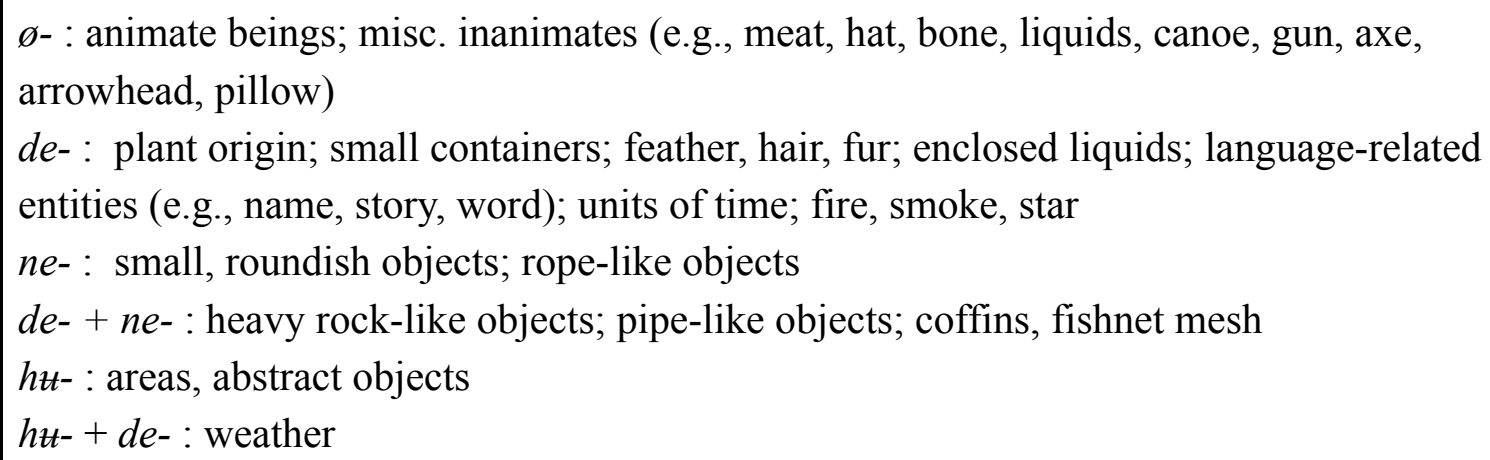

Every noun in the language falls into one of these categories, and can therefore be assigned one of these gender markers. The main function of the gender markers is to encode the gender, and therefore physical traits, of the argument which precedes it. Otherwise, both the noun and its gender prefix may be replaced by a pronoun prefix such as ye-.

$$
\begin{aligned}
& \text { a. k'etsaan' degheet'otl } \\
& k \text { 'etsaan' de- ghe-(n)e- ø- } \quad \text { - } t \text { 'otl } \\
& \text { grass } \quad \mathrm{G}_{\text {plant }}-\mathrm{M}_{\mathrm{PRF}}-\mathrm{PRF}-\text { 3SG.SUBJ- } \mathrm{CL}_{\varnothing} \text { - cut.DUR.PRF } \\
& \text { 'He cut grass' }
\end{aligned}
$$

\footnotetext{
${ }^{29}$ Thompson (1993), however, makes a convincing argument for treating the areal prefix $h u-$ on the separate terms which its unique distribution (e.g., it is more readily used as an argument than other gender prefixes) seems to call for. This is in addition to supporting evidence from neighboring languages.
} 
b. yegheet'otl

ye- ghe- $(n) e-\varnothing-\quad$ o- t'otl

3SG.OBJ- $\mathrm{M}_{\mathrm{PRF}}$ - PRF- 3 SG.SUBJ- $\mathrm{CL}_{\varnothing}$ - cut.DUR.PRF

'He cut it'

\subsubsection{Object(s)}

Many verb themes call for objects. This requirement need not be satisfied with full noun phrases, but can often, when discourse allows for it, be satisfied merely with pronoun prefixes.

Table 8. Object pronoun prefixes in Koyukon.

\begin{tabular}{|l|c|c|}
\hline Person & singular & plural \\
\hline 1 & se- & denaa- \\
\hline 2 & $n e-$ & $y z h-$ \\
\hline 3 & $b e-, y e-, \varnothing-$ & hebe- \\
\hline Indef. & \multicolumn{2}{|c|}{$k^{\prime} e-$} \\
\hline
\end{tabular}

These pronominal prefixes attach to the verb, in the case of direct objects, in the zone immediately preceding (i.e., to the left of) the qualifier zone.

(28) a. yeneeł'aanh

$y e-\quad n e-\quad(n) e-\quad \varnothing-\quad t-\quad$ 'aan $\quad-(n) h$

1SG.OBJ- QUAL- IMPRF- 1SG.SUBJ- CL- look.DUR -IMPRF

'(S)he is looking at it, him'

b. yoolaatltl'onh

$y(e)-\quad o o-\quad l(e)-\quad(l e)-\quad \varnothing-\quad t-\quad t l^{\prime} o n \quad-(n) h$

3SG.OBJ- QUAL- QUAL- $\mathrm{M}_{\mathrm{IMPRF}}{ }^{-}$3SG.SUBJ- $\mathrm{CL}_{\mathrm{r}}$ - hear.NEU -IMPRF

'(S)he understands, listens to him, her' (theme: $\mathrm{O}+\mathrm{oo}+\mathrm{le}+\mathrm{l}+\mathrm{tl}^{\prime}$ 'on 'listen to $\mathrm{O}$ ') 
Taking the verb in $a$, and expanding to include full noun phrases for comparison, consider the following clauses.

(29) a. Mary John neeł'aanh

Mary John ne- $\quad$ (n)e- $\quad$ - $\quad t-\quad$ 'aan $\quad-(n) h$

Mary John QUAL- IMPRF- 1SG.SUBJ- $\mathrm{CL}_{\mathfrak{f}}$ - look.DUR -IMPRF

'Mary is looking at John'

b. Mary yeneet'aanh

Mary ye- ne- (n)e- $\varnothing-\quad t-\quad$ 'aan $\quad-(n) h$

Mary 1SG.OBJ- QUAL- IMPRF- 1 SG.SUBJ- $\mathrm{CL}_{\uparrow}-$ look.DUR -IMPRF

'Mary is looking at him'

In $a$, explicitly stating the direct object 'John' satisfies the verb theme's requirement for an object. However, without stating the direct object overtly, as in $b$., the third-person singular object pronoun ye- is required. The use of an object prefix, however, is governed by the subject. For example, when there is a first-person singular subject, the direct object is not marked overtly, as it is in example (29) above, and $b$. below.

a. letltseenh

[ ø- ]le- (es)- (t)- tsee $\quad-n h$

[OBJ-] $\mathrm{M}_{\mathrm{PRF}}-1 \mathrm{SG} . \mathrm{SUBJ}-\mathrm{CL}_{\uparrow}-$ make.sg.O.DUR -PRF

'I made it'

b. yeetltseenh

ye- (le)- ø- $\quad t-$ tsee $\quad-n h$

3SG.OBJ- $\mathrm{M}_{\mathrm{PRF}}-3 \mathrm{SG} . \mathrm{SUBJ}-\mathrm{CL}_{\uparrow}-$ make.sg.O.CONC -PRF

'(S)he made it'

*'I made it'

Because there is an overt object pronoun ye- in the second verb above, yeetltseenh cannot be interpreted to mean *'I made it,' and instead can only mean that some third-person subject 'he, 
she, or it' made it. As Thompson (1989) points out, the object prefix is also omitted with the use of the first-person plural and indefinite subject $t s^{\prime} e$-, though not with the third-person plural subject $h e-.^{30}$

a. ts'eneeł'aanh

[ø- $\quad t s^{\prime} e^{-} \quad n e-\quad(n) e-\quad t-\quad$ 'aan $\quad-(n) h$

[OBJ-] 1PL.SUBJ- QUAL- IMPRF- $\mathrm{CL}_{\mathfrak{r}}-$ look.DUR -IMPRF

'We are, someone is looking at it, him'

(adapted from Thompson, 1989: 11)

b. heyeneel'aanh

he- $y e-\quad n e-\quad(n) e-\quad \varnothing-\quad t-\quad$ 'aan $\quad-(n) h$

3PL.SUBJ- 1SG.OBJ- QUAL- IMPRF- 1SG.SUBJ- CL $L_{\mathfrak{r}}$ look.DUR -IMPRF

'They are looking at it, him'

Another subsystem within the pronominal system in Koyukon, and one that is perhaps more characteristic of the Athabaskan family as a whole ${ }^{31}$, is the alternation between the object prefixes ye- and be-. Consider the following examples.

a. yeneeł'aanh

$y e-\quad n e-\quad(n) e-\quad \varnothing-\quad t-\quad$ 'aan $\quad-(n) h$

1SG.OBJ- QUAL- IMPRF- 1SG.SUBJ- $\mathrm{CL}_{\mathrm{f}}$ - look.DUR -IMPRF

'She is looking at him'

b. beyeneeł'aanh

be- $y e-\quad n e-\quad(n) e-\quad \varnothing-\quad t-\quad$ 'aan $\quad-(n) h$

1SG.OBJ- 3SG.SUBJ- QUAL- IMPRF- 1SG.SUBJ- $\mathrm{CL}_{\uparrow}-$ look.DUR -IMPRF

'She $(y e)$ is looking at him (be)'

\footnotetext{
${ }^{30}$ See section Cook (1996) for a discussion of how third-person plural subjects attach onto the verb in Northern Athabaskan languages.

${ }^{31}$ There have been several studies related to this alternation in Navajo. See Thompson (1989) for some of this discussion, and how it relates to the similar alternation in Koyukon. For an approachable introduction to the structure of Navajo verbs, see Faltz (1998).
} 
The general meaning between the two examples above remains the same, but the number of pronouns, and the alignment between those pronouns and their referents, have changed. Notice that $y e$ - in $a$. corresponds to the object 'him,' while the subject 'she' is predictably encoded by the phonologically null ø-, positioned to the left of the classifier. In $b$., however, the object prefix behas been introduced, and has 'stolen' the direct object 'him.' The pronoun ye-, now lacking a referent, then adopts the subject 'she.'

An explanation for introducing be- and shifting argument referents around is difficult to make on the basis of syntax alone. The general meaning between the two is, after all, renderable in English as being the same. However, such an alternation does mark a pragmatic change in Koyukon (Thompson, 1989). Under a pragmatic or functionalist lense, the introduction of the bepronoun serves to topicalize or discursively 'emphasize' the direct object. The unusualness (i.e., markedness) of the be- pronoun in this alternative morpho-syntactic structure serves to highlight or 'promote' its referent to a degree that it does not otherwise enjoy under the 'normal' morpho-syntactic construction. These alternations are, however, not extremely common.

\subsubsection{Disjunct prefixes}

To the left of the pronominal zone begins a region of the template that is distinguishable from those before it (i.e., to the right of it, or the so-called 'conjunct' prefixes). This distinction can be made on a number of grounds. Prefixes to the left of the conjunct prefixes, for example, do not undergo the same morpho-phonological transformations as the conjunct prefixes. Additionally, many of the prefixes on this far end of the verb template are much more transparent in their meaning than qualifiers. In some cases, they are transparent because they represent 
incorporated noun or verb stems which may stand independently elsewhere in the language, or are members of a number of postpositions which require their own postpositional objects, and are therefore debatable as being better considered prefixes, or members of their own lexical class. These sorts of prefixes are termed the 'disjunct' prefixes.

Thompson (1977), basing his account in part on the work of Jetté's unpublished grammar, lists five possible categories for disjunct prefixes: incorporates, the 'reduplicative,' what Jetté labels the 'essential' prefixes, adverbials, and postpositions. For the present introduction, however, some of these categories may be conflated with one another under the general label 'thematic,' and others, such as the 'reduplicative,' saved for later sections on derivation.

\subsubsection{Thematic prefixes and incorporates}

In addition to a stem, classifier, and sometimes objects and qualifiers, some verb themes require additional morphemes which appear to the left of qualifiers. As part of the verb theme, these thematic prefixes are better considered to contribute to the verb theme's basic verbal meaning, rather than independently modifying the meaning laid down by other elements. That said, some of these thematic prefixes are more or less easily recognized as being roots themselves elsewhere in the language. Compare, for example, a sentence including the noun 'sleep' alongside a separate verb with a sentence that contains the verb theme meaning 'sleep.'

(33) a. sebele' aahudesneek

se- $b e(t)-e^{\prime} \quad a a-h t-d e-(e) s-\varnothing-n e e k$

$1 \mathrm{SG}-$ sleep -POSS T- OBJ ${ }^{32}$ - QUAL- 1 SG.SUBJ- $\mathrm{CL}_{\varnothing}$ - move.hand.PRF

'I have used my sleep'

\footnotetext{
${ }^{32}$ This verb theme requires the object $h t^{-}$, and is therefore said to be a 'thematized gender'
} 
b. bełnegetenh

bet-ne- $\varnothing-\quad(e s)^{33}-\quad(l e)-\quad$ ten $\quad-(n) h$

T- QUAL- $\mathrm{M}_{\mathrm{IMPRF}}-1 \mathrm{SG} . \mathrm{SUBJ}-\mathrm{CL}_{1+\mathrm{D}}$ - sleep.DUR -IMPRF

'I am sleeping' (theme: beł+ne+le+ten 'sleep')

Here, the import of the noun meaning 'sleep' is transparent. However, that does not take away from its importance. Replacing the thematic bet\# with an the terminative nee\# would not mean to stop sleeping, but to lose one's patience. Clearly, the meaning of the theme bet+ne+le+ten 'sleep' cannot be attributed to the stem alone, or even the stem, classifier, and qualifier ne-.

While some incorporated nouns are present in inflected verbs because they are required by the verb theme, others may show up in verbs as part of grammatically optional derivational strings (DS) to change the meaning of the verb. One such example, which appears in many derived verbs, is taa\#, which is related to the noun too 'water.'
a. taaneeyo
taa-ne- (ne)- ø- $\varnothing-\quad$ yo
DS- $\mathrm{M}_{\mathrm{PRF}}-\mathrm{PRF}-3 \mathrm{SG} . \mathrm{SUBJ}-\mathrm{CL}_{\emptyset}$ - sg.goes.MOM.PRF
'(S)he dove into the water'
b. taal'onh
taa-l(e)- $\varnothing-\quad \varnothing-\quad ' o \quad-n h$
DS- $\mathrm{M}_{\mathrm{IMPRF}}$ - $3 \mathrm{SG} . \mathrm{SUBJ}-\mathrm{CL}_{\varnothing}$ - handle.compact.O.MOM-IMPRF
'It (fishnet) is set in water'

There are other prefixes like bel\# and taa\# which are transparently roots which have been ossified into particular derivations. Many of these thematic prefixes share certain semantics, with

\footnotetext{
${ }^{33}$ Here, the first-person singular es- + le- $\rightarrow$ ege-
} 
noun stems relating to body parts, time, and materials all found in abundance affixed onto verbs to convey the relation of certain nominal entities and the actions denoted by the verb stem. ${ }^{34}$

\subsection{Mode and aspect}

Although tense, mood, and aspect constitute discrete theoretical categories in general linguistic theory, all languages differ in part with respect to their treatment of these categories. In Koyukon, these categories, falling under the broad label of 'mode,' are not so easily delineated from one another. Whether an action is complete or not from a speaker's perspective is traditionally an aspectual distinction, and is therefore, theoretically, not mutually exclusive with other categories that mark when that action has taken, will take, or is presently taking place (i.e., tense), or, generally, what the speaker thinks or feels about the action (mood). Koyukon, however, conflates these three categories onto a single plane, so that an action either (1) is incomplete, or in the process of being done (i.e., imperfective), (2) has been done, or is being considered as a whole, discreetly started and/or completed action (i.e., perfective), (3) is something which the speaker intends to do (i.e., future), or (4) is something that the speaker wants to do, or to have happen (i.e., optative).

Each of these mutually exclusive modal distinctions in Koyukon has their own complexities, and requires the cooperation of more than one slot in the verb template. There is, however, one slot with the sole function to mark only one of these four modes. This slot is appropriately labeled the 'mode' slot, and comes to the left of the singular subject prefix in most verbs.

\footnotetext{
${ }^{34}$ See Axelrod (1990) for a discussion devoted to the topic of what sorts of verbs may take incorporates, and the function that those incorporates play.
} 
a. estseh

$$
\begin{aligned}
& \text { o- } \quad e s-\quad \varnothing-t s e h \\
& \mathbf{M}_{\text {IMPRF }}-1 \text { SG.SUBJ- } \mathrm{CL}_{\varnothing}-\text { cry.DUR.IMPRF } \\
& \text { 'I'm crying' (imperfective) }
\end{aligned}
$$

b. ghestsaah

ghe- $(e) s-\quad \varnothing-$ tsaah

$\mathbf{M}_{\mathrm{PRF}^{-}}$1SG.SUBJ- $\mathrm{CL}_{\varnothing}$ - cry.DUR.PRF

'I cried' (perfective)

c. k'etołyoyh

$k^{\prime} e^{-} \quad t(e)-\quad(\text { ghe })^{35}-\varnothing-\quad t-y o y h$

INDEF.OBJ- INCEP- $\mathbf{M}_{\mathrm{FUT}^{-}} \quad$ 3SG.SUBJ- $\mathrm{CL}_{\tau}-$ toast.CONC.FUT

'(S)he will toast, smoke something' (future)

d. k'eghoołyoyh

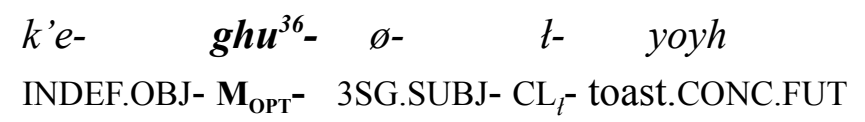

'(S)he should toast, smoke something' (optative)

(examples $c$. and $d$. adapted from Axelrod, 1993: 41)

Although there are multiple abstract distinctions that the modal prefix makes, there is one primary distinction between the perfective and imperfective modes and the future and optative modes. This is a distinction between 'realis' and 'irrealis,' or the distinction between actions that have taken or are taking place in the real world, and actions which can only be spoken of in a subjunctive, hypothetical sense. Speakers of Koyukon can then further distinguish between

\footnotetext{
${ }^{35}$ Per a morpho-phonological rule (Thompson, 1977: 86), the future modal prefix ghe- has been absorbed by the preceded inceptive qualifier $t e$ - to produce the surface form to-.

${ }^{36}$ The difference in form between the surface ghoo- and the underlying ghu-can be attributed to a similar absorption rule to to- above, although here $g h u$ - has absorbed an irregular prefix $(n) e$ - which accompanies some verbs with a third-person singular subject.
} 
real-world actions as being complete (perfective) or in-progress (imperfective), as well as hypothetical actions which are favorable (optative) or intended (future).

One important observation to make with the previous four examples is that the modal prefix is not the only component of the verb doing the work of categorizing the action into one of four modes. The future ghe-, for example, requires the cooperation of the inceptive qualifier ${ }^{37} t$ to mark the future mode.

$$
\begin{aligned}
& \text { a. taagheskkaał } \\
& \text { t(e)- ghe- (e)s- } \text { ø- }^{-\quad k k a a t} \\
& \text { INCEP- } \mathrm{M}_{\mathrm{FUT}}-1 \mathrm{SG} . \mathrm{SUBJ}-\mathrm{CL}_{\varnothing} \text { - sg.paddle.DUR.PROG } \\
& \text { 'I will paddle, go by boat' } \\
& \text { b. gheskkaał } \\
& \text { ghe- (e)s- ø- kkaat } \\
& \mathrm{M}_{\mathrm{IMPRF}}{ }^{-} \text {1SG.SUBJ- } \mathrm{CL}_{\varnothing} \text { - sg.paddle.DUR.PROG } \\
& \text { 'I am paddling, going by boat' }
\end{aligned}
$$

Similarly, all modal prefixes must coordinate with the appropriate verb stem, which includes an aspect suffix. Consider the difference in form and meaning between the suffix $-n h$ and the glottal suffix - .

a. seneeł'aanh

$$
\begin{aligned}
& \text { se- nee- } \varnothing-\quad t \text { - 'aan } \quad-(n) h \\
& \text { 1SG.OBJ- QUAL- 3SG.SUBJ- } \mathrm{CL}_{\uparrow}-\text { look.DUR -IMPRF }
\end{aligned}
$$

'(S)he is looking at me'

b. seneeł'aan'

$$
\begin{aligned}
& \text { se- nee- ø- } t \text { - 'aan -' } \\
& \text { 1SG.OBJ- QUAL- 3SG.SUBJ- } \mathrm{CL}_{1}-\text { look.DUR -PRF }
\end{aligned}
$$

'(S)he looked at me'

\footnotetext{
${ }^{37}$ See section 3.1.3 for how the inceptive prefix te- is a unique qualifier with respect to its function. In short, this prefix is much more grammatically operative than other qualifiers in the same prefix zone.
} 
Between these two verbs, the only overt (i.e., not phonologically null) marker of mode is the suffix, with - $n h$ marking the imperfective aspect and -' marking the perfective.

In addition to the modal prefix, the aspectual suffix, and, in the case of the future mode, the inceptive prefix, there is one last verb slot that serves to mark a perfective-imperfective distinction. This prefix, called the 'y-element' in Athabaskanist literature (Krauss, 1969; Faltz 1998; Thompson, 1977), is positioned between the modal prefix and the singular subject marker, and is somewhat irregular. It is coordinated with the suffix - $n h$ to alone form the imperfective in neuter verbs, as in $a$. below, or combine with the $n e$ - modal prefix to form the perfective, as in $b$. below. Its presence very commonly triggers various morpho-phonological rules which result in the deletion of its nasal consonant and compensatory vowel lengthening on a preceding affix.

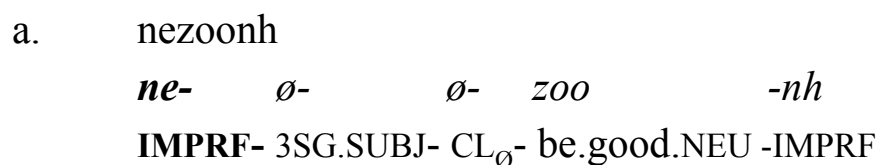

'It is good'

b. yeenee'onh

ye- $\quad n e-($ ne) $-\varnothing-\quad \varnothing-\quad ' o \quad-n h$

3SG.OBJ- $\mathrm{M}_{\mathrm{PRF}}$ - PRF- 3SG.SUBJ- $\mathrm{CL}_{\varnothing}$ - handle.compact.O.MOM -PRF

'He brought it'

Here, discerning between $n e$ - imperfective and $n e$ - perfective involves both noting the presence of the modal prefix $n e$ - in $b$, as well as recognizing the active status of the second verb as being separate from the non-active (i.e., neuter) status of the first. With these last examples, it should be more or less apparent that expressing one of four modal distinctions in Koyukon involves the coordination between multiple components of the verb template on both sides of the stem; 
namely a modal prefix, a more evasive (im)perfective prefix, an aspect suffix, and, for the future mode, an inceptive qualifier.

The examples above also exhibit another, perhaps more daunting component of the modal system of Koyukon. While multiple slots are tasked with conveying any one mode, any one mode may have multiple prefixes for any one slot. In other words, mode is differentiated using multiple simultaneous prefixes as well as multiple forms for each of those prefixes. To exacerbate potential confusion, many of those various mode-conveying prefixes are phonologically identical (i.e., homophonous) with others that carry a separate function. A ne-, $l e$-, or ø- prefix may mark the perfective mode in one verb and the imperfective in another, as can both the $n e-$ 'y-element' prefix and - $n h$ suffix, as visible above. Consider the following verbs, all of which contain the mode prefix ghe-.

a. gheskkaał

ghe- (e)s- ø- kkaa-t

$\mathbf{M}_{\text {IMPRF}}$ - 1 SG.SUBJ- $\mathrm{CL}_{\emptyset}$ - sg.paddle.DUR -PROG

'I am paddling, going by boat' (progressive, imperfective)

b. gheslaa'

ghe- $(e) s-\quad \varnothing-$ la - $^{\prime}$

$\mathbf{M}_{\mathbf{P R F}}-1$ SG.SUBJ- $\mathrm{CL}_{\varnothing}$ - be.NEU -PRF

'It was' (perfective)

c. taagheskkaał

$t(e)$ - ghe- $(e)_{s-} \quad$ ø- $k k a a-t$

INCEP- $\mathbf{M}_{\mathrm{FUT}^{-}}$1SG.SUBJ- $\mathrm{CL}_{\varnothing}$ - sg.paddle.DUR -PROG

'I will paddle, go by boat' (future) 
Although phonologically identical, the ghe- prefixes above interact with other components in the verb to convey different modes. Now consider the next three examples, all of which being in the imperfective mood, but with three different modal prefixes.

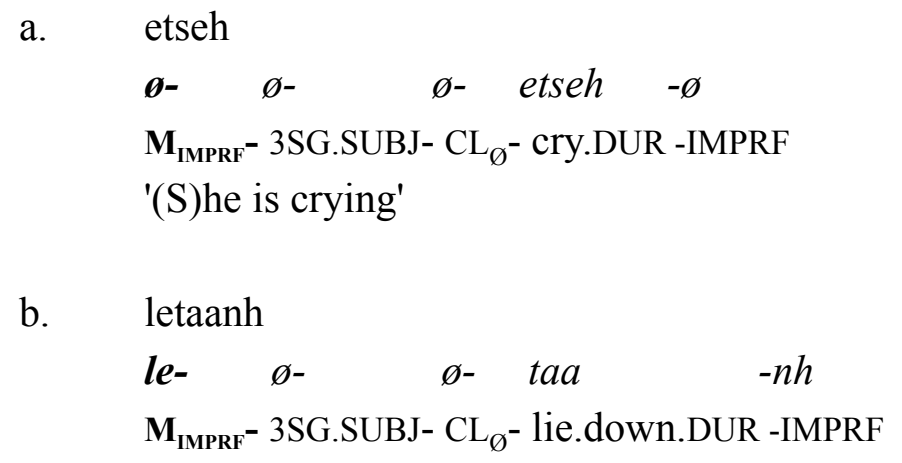

'(S)he is lying down'

c. neełtaayh

ne- (ne)- $t$ - taa $-y h$

$\mathbf{M}_{\text {IMPRF }}$ - 2SG.SUBJ- $\mathrm{CL}_{\mathrm{f}}$ - handle.animate.O.DUR -IMPRF

'You bring him'

Here, three separate modal prefixes are used to categorize the verb into the imperfective mood. This may serve to contrast against the verbs in example (40) above, in which the same modal prefix marked three separate modes.

\subsubsection{Mode and modal strings}

The confusion resulting from laying out these seeming morpheme-category contradictions can be partially mitigated by considering modal prefixes and other mode-conveying affixes as constituting a functional unit. In other words, in the same way that lexical meaning is ascribed to the verb theme as a whole, mode may be considered as being 
conveyed by a single unit constituted by multiple, discontinuous parts that attach themselves to different places of the verb. This consolidates much, though not all, of the variation in modal morphology into a nine modal affix strings, which may be assembled as follows:

\begin{tabular}{|c|c|}
\hline imperfective & $\begin{array}{l}\varnothing+\varnothing+\text { stem }+\varnothing \\
\text { ne+Ø+stem }+ \text { yh } \\
\varnothing+\text { ne }+ \text { stem }+ \text { nh } \\
\text { ghe }+\varnothing+\text { stem }+1\end{array}$ \\
\hline perfective & $\begin{array}{l}\text { ne }+ \text { ne }+ \text { stem }+ \text { nh } \\
\text { le }+\varnothing+\text { stem }+ \text { nh } \\
\text { ghe }+ \text { ne }+ \text { stem }+ \text { nh/' }\end{array}$ \\
\hline future & te + ghe $+\varnothing+$ stem $+1 / 1$ \\
\hline optative & ghu $+\varnothing+$ stem ${ }^{\prime}$ \\
\hline
\end{tabular}

By codifying these modal strings into units like verb themes, a more in-depth discussion of the distribution and function of both the 'y-element' ne- and the suffixes - $n h,-$ ', -ø, and $-t$ may be put off until a different discussion. What is still left unexplained, however, is what determines which modal string any given verb might take.

There have been various explanations given for matching certain verbs with certain modal strings. Krauss (1969), for instance, through a cross-linguistic analysis of the multiple perfectives in other Athabaskan languages and neighboring languages Eyak and Tlingit, has gleaned a semantic distinction between what corresponds to Koyukon's le-, ghe-, and neperfective modal prefixes. Thompson (1977) makes no argument against this, but instead offers that any one perfective, which seems to have lost this meaning distilled by Krauss' analysis, is 
"specified in the lexical entry of the verb theme" (36). This explanation is certainly convenient, although the theoretical strength of the verb theme is not obviously capable of supporting whatever information may be discarded onto it. Axelrod (1993) presents a much heartier alternative, although one that is predicated on a deeper understanding of Koyukon aspect than has thus far been provided.

\subsubsection{Koyukon aspect}

In order to understand how verbs govern the use of aspectual morphology in Koyukon, at least according to Axelrod (1993; Axelrod and Jones, 1989), the concept of 'aspect' must be attended to, as it concerns Koyukon morphology. Until this point, 'aspect' has been used to denote things that include a distinction between perfective and imperfective. While this is not technically an abuse of the term, it might be helpful instead to cut ties between this perfective distinction and the label 'aspect,' and instead consider perfective versus imperfective to simply be a 'modal' distinction. With the freedom that is thereby granted to the term 'aspect,' consider the following stem sets, all deriving from the verb root meaning 'chop.'

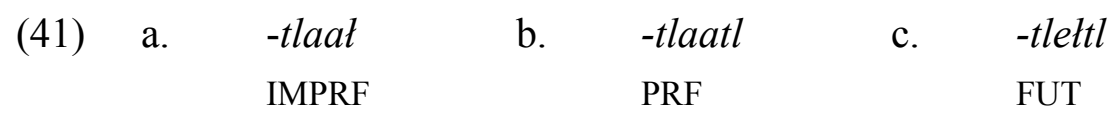

As would be expected from the discussion on stems in section 4.1.1, these stems are different from one another, on the functional basis of encoding a different modal conjugation. However, these stem sets do not encode simply the verbal meaning 'chop' as well as their respective modal distinctions. There is another semantic element encoded in the form of these stems. That element 
refers to the nature of the action itself. In the case of these three stem sets, that meaning highlights the manner of movement or execution of the activity of chopping. This third layer of meaning is what shall be called 'aspect,' and this particular 'aspect' shall be called the 'momentaneous' (MOM).

The label 'aspect,' used in this way, tangents the theoretical category of 'Aktionsart,' or 'lexical aspect,' in that the meaning regarding the action is subsumed within the nature inherent to that particular verb ${ }^{38}$. However, this widely accepted use of 'aspect' in Athabaskan languages is unique from 'Aktionsart' in that a different aspect of an action may be highlighted, such as to stress, for example, the abrupt and singular execution of an activity. The stem sets in order to highlight this aspect, called the 'semelfactive' (SEM), are as follows.
a. $\quad$-tlet
b. tlet
c. tlet
IMPRF
PRF
FUT

As is quite obvious, the stem sets used to express the semelfactive aspect of an action are phonologically identical regardless of modal distinction. However, the difference in phonological form between the two stem sets above serves the distinction of highlighted aspect — the useful function of which is made apparent in the comparison of two full verbs with different stem shapes.

$$
\begin{aligned}
& \text { a. yegheetlaatl } \\
& \text { ye- ghe- }(n) e-\varnothing-\quad \varnothing-\quad \text { tlaatl } \\
& \text { 3SG.OBJ- } \mathrm{M}_{\mathrm{PRF}} \text { - PRF- } 3 \mathrm{SG} . \mathrm{SUBJ}-\mathrm{CL}_{\varnothing}-\text { chop.MOM.PRF }
\end{aligned}
$$

'(S)he chopped it'

\footnotetext{
${ }^{38}$ The split-second duration of a sneeze, for example, may be said to fall under the 'Aktionsart' of the verb word SNEEZE. A single sneeze can not be stretched out over time in the same way that singing or walking can, and a speaker of a language knows this when they know the word SNEEZE.
} 
b. yegheetletl

ye- $\quad$ ghe- $(n) e-\varnothing-\quad \varnothing-\quad$ tletl

3SG.OBJ- $\mathrm{M}_{\mathrm{PRF}}$ - PRF- 3SG.SUBJ- $\mathrm{CL}_{\varnothing}$ - chop.CONS.PRF

'(S)he chopped it repeatedly'

c. yeeltleł

ye- le- $\varnothing-\quad$ o- tlet

3SG.OBJ- $\mathrm{M}_{\mathrm{PRF}}-3 \mathrm{SG} . \mathrm{SUBJ}-\mathrm{CL}_{\varnothing}-$ chop.SEM.PRF

'(S)he chopped it once'

These examples showcase the utility of such a robust aspect system. While the argument structure remains the same for all three verbs, semi-adverbial information, only renderable with separate adverbs in English, is encoded in the verb stem itself along with the modal distinction.

\subsubsection{The interaction of mode and aspect}

One last observation about the three verbs above returns the discussion back to the selection of modal string. Notice that, although the verb theme $\mathrm{O}+\mathrm{G}+$ tlaatl 'chop $\mathrm{O}$ ' remains consistent through all three verbs, the modal strings required to categorize the verb into a the perfective mode changes from the ghe-perfective with the first two verbs to the $l e$ - perfective with the final verb. Axelrod (1993) contends that the situationally optimal aspect of the verb stem, and not the verb theme, as Thompson (1977) suggests, determines the choice of modal string. In other words, the first two verbs above take the ghe-perfective because both the momentaneous (MOM) and the consecutive (CONS) aspects call for it. Likewise, the semelfactive aspect (SEM) governs the use of the le-perfective for yeeltlet. The various aspects of Koyukon, fifteen in all, can therefore be listed below ${ }^{39}$.

\footnotetext{
${ }^{39}$ See list of abbreviations for all aspects.
} 
Table 10. Koyukon aspect by governed perfective modal prefix category.

\begin{tabular}{|l|l|l|l|}
\hline$l e+\varnothing+$ stem $(+n h)$ & ghe $+n e+s t e m+n h /^{\prime}$ & $\varnothing-$ & $n e+n+$ stem $+n h$ \\
MOM & MOM & MOM & MOM \\
TRANS & REV & TRANS & \\
REV & DUR & & \\
SEM & CONS & & \\
BIS & REP & & \\
CNCL & DIR-REP & & \\
CONT & PERS & \\
PRMB & PROG & & \\
DIST & CUST & & \\
& NEU & & \\
\hline
\end{tabular}

(adapted from Axelrod 1993: 36)

\subsubsection{Summary}

Koyukon distinguishes between actions that have taken, or are taking place in the world (i.e., realis), and those that are merely hypothetical (i.e., irrealis). With non-hypothetical actions, Koyukon distinguishes between verbs that, from the speaker's perspective, are complete (i.e., perfective) or in-progress (i.e., imperfective). With hypothetical actions, Koyukon marks a distinction between those that are intended (i.e., future), or favorable to the speaker (i.e., optative). These categories — the imperfective, the perfective, the future, and the optative — are the four modal distinctions of Koyukon.

These modal distinctions are marked by a number of components in the verb template. These include the verb stem and its suffix, a mode prefix, an irregular perfective prefix known as the 'y-element,' and finally, in the case of the future mood, the inceptive qualifier te-. These components cooperate to categorize a verb into one of the four modes of Koyukon. For this reason, any inflected, 'grammatical' verb may be analyzed as having a string of mode-conveying affixes that are united on an abstract level, much in the same way that verb themes are. These may be termed 'modal strings' for the sake of convenience. 
There are multiple modal strings for the perfective and imperfective modes, the selection of which is governed by the choice of aspect to be highlighted by a particular verb stem. Every verb stem has multiple forms, each of which encodes, in addition to its verbal meaning, (1) the mode of the action, as well as (2) the particular aspect of the action which is to be highlighted. There are fifteen aspects in Koyukon. Both aspect and mode combine to enable Koyukon verbs with a robust system of expressing a nuanced nature of verbal actions.

\section{Additional derivation}

As the previous section illustrates, between the elements required by the verb theme (e.g., qualifiers, objects, disjunct prefixes, etc.) and the obligatory marking of verbal actions for one of both four modes and fifteen aspects, minimal verbs in Koyukon offer a highly engineered and nuanced notion of verbal action. However, Koyukon also allows for additional, grammatically optional morphology which serves to modify or contribute to the meaning of the base verb. In Koyukon, these additional layers of morpho-semantics fall into three categories: aspectual derivation, superaspect, and non- or post-aspectual derivation. These three derivational categories can be differentiated on the bases of both the meaning which they impose on the verb, as well as their interaction with the verb's modal and aspectual categories, and with other derivational strings. They combine with the obligatory categories of mode and aspect for a total of five derivational categories in Koyukon. 


\subsection{Aspectual derivation}

Aspectual derivation refers to affixes or 'strings' of affixes that attach to a verb to impose an additional meaning onto the action that it denotes. This additional meaning may emphasize the duration or direction of an activity, the positioning of the subject with respect to something else, or other components related to the doing of the action itself. In the verbs below, notice the additional morphology of the aspectual derivation strings (DS) and the effect that they in part superimpose over the meaning of the verb theme $\mathrm{O}+\mathrm{G}+\varnothing+$ tlaatl 'chop $\mathrm{O}$ '.
a. yeeltleł
ye- le- $\varnothing-\quad$ o- tlet
3SG.OBJ- $\mathrm{M}_{\mathrm{PRF}}-3 \mathrm{SG} . \mathrm{SUBJ}-\mathrm{CL}_{\varnothing}-$ chop.SEM.PRF

'(S)he chopped it once'

b. neeyeeneetlaatl

nee- ye- ne- (n)- $\varnothing-\quad \varnothing-\quad$ tlaatl

DS- 3 SG.OBJ- $\mathrm{M}_{\mathrm{PRF}}$ - PRF- 3SG.SUBJ- $\mathrm{CL}_{\varnothing}$ - chop.MOM.PRF

'(S)he chopped it up into pieces'

c. hoyedegheetlaatl

ho-ye- de-ghe-(n)e- ø- $\quad$ - tlaatl

DS- 3SG.OBJ- DS- $\mathrm{M}_{\mathrm{PRF}}$ - PRF- 3SG.SUBJ- $\mathrm{CL}_{\varnothing}$ - chop.MOM.PRF

'(S)he chopped it all over the area'

While $a$. lacks any additional derivation, $b$. contains the affix nee- and differs from $a$. in that it denotes the specific result of the chopping, 'into pieces.' Likewise, the verb in $c$. has not one, but two additional morphemes, ho- and de-, which perform the work of denoting the spatially widespread outcome of the action, 'all over the area.' Notice also that these morphemes do not attach onto the same place within the verb. The second component, de-, affixes between the 
object and the modal marker, while ho-, like nee- in b), attach onto the far side of the verb from the stem, or on the other side of the disjunct boundary (\#). However, a difference in meaning, or at least function, between ho- and de- is difficult to ascribe, and so these together are better treated as a single unit or 'string' of discontinuous morphemes, which together contribute a single shade of meaning.

It is also crucial to note that a change in aspectual derivation has also accompanied a change in modal string. While the derivationally bare verb in $a$. has a $\varnothing$-perfective modal string, the verb in $b$. has a $n e$ - perfective string, and in $c$., a ghe- perfective string. Notice also that, as a part of those perfective strings, the aspect which governs them has changed. The first verb is in the semelfactive (SEM) aspect, while both $b$. and $c$. are in the momentaneous (MOM) aspect. ${ }^{40}$ In the same way that aspect governs the choice of modal string, these derivational strings governs the choice of aspect - and therefore also the choice of modal string. For this reason, these derivational strings are labeled 'aspectual derivation,' or 'aspect-dependent derivational strings.' They rely on the use of a verb's most common, prototypical aspectual designation (Axelrod, 1993).

Because these verbs undergo a change in modal string that is specific to the derivational string, the choice of modal string is considered, at least in the Jetté, Jones, and Kari (2000), to be encoded within the abstract derivational string itself. In other words, the two derivational strings above would be codified as nee\# $n$ mom and ho\#de gh mom., respectively (ibid: 568). This also accounts for the fact that aspectual derivational strings may not co-occur on the same verb they might conflict with regards to their preferred aspectual distinction. This is, of course, to say

\footnotetext{
${ }^{40}$ Recall from table 10 above in section 3.2. That the momentaneous aspect may accommodate both a ne- as well as a ghe- modal string.
} 
nothing about a potential conflict of semantics, which has been the focus of at least one in-depth discussion (Axelrod, 1993).

\subsection{Superaspect}

Unlike aspect-dependent derivation, other additional aspect-modifying affixes seem to be able to attach themselves onto verbs that already have additional aspectual derivation. There are much fewer individual derivational units of this kind compared to aspect-dependent strings four, in fact. They are, however, very common in the language. They may be used to emphasize (1) the plurality of either the locations at which an action occurs or (2) of the participants involved, (3) the habitual recurrence of an action, or (4) the duration or progress of the action. These four derivational strings are called 'superaspects,' in that they may superimpose meaning over an already aspectually derived verb. See the following examples of each of these superaspectual strings with the verb theme beł\#ne+le+daakk 'fall asleep,' adapted from Axelrod (1993: 88-89).

a. bełnaadledaakk

bet- ne-le- ø- le- daakk

$\mathrm{T}_{\text {'sleep' }}$ T- $\mathrm{M}_{\mathrm{PRF}}-3 \mathrm{SG} . \mathrm{SUBJ}-\mathrm{CL}_{1+\mathrm{D}}-$ experience.MOM.PRF

'(S)he fell asleep'

b. nebełheenaadledaakk

ne-bet- he- ne-le- le- daakk

DS- $\mathrm{T}_{\text {'sleep' }}$ 3PL.SUBJ- T- $\mathrm{M}_{\mathrm{PRF}^{-}}-\mathrm{CL}_{1+\mathrm{D}}$ - experience.DIST

'They fell asleep here and there'

c. yenbełheenaadledaakk

yen-bet- he- ne-le- le- daakk

DS- $\mathrm{T}_{\text {'sleep' }}$ - 3PL.SUBJ- T- $\mathrm{M}_{\mathrm{PRF}}-\mathrm{CL}_{\mathrm{H}+\mathrm{D}}$ - experience.MULT

'They (group of people) fell asleep' 
d. nobeł'eetenledeh

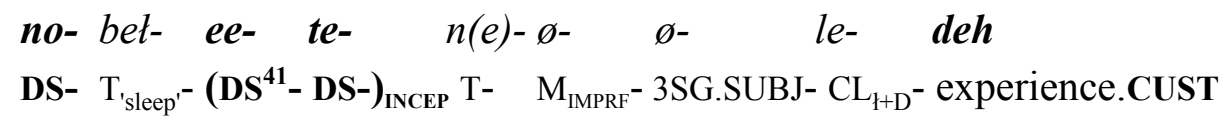

'(S)he keeps falling asleep'

e. bełnoldehtl

bet- $n(e)-(g h e)-\varnothing-\quad$ le- dehtl

$\mathrm{T}_{\text {'sleep'- }}$ T- $\quad \mathrm{M}_{\mathrm{PRF}^{-}}$3SG.SUBJ- $\mathrm{CL}_{\mathrm{l}+\mathrm{D}^{-}}$experience.PROG

'(S)he is falling asleep'

As the above examples show, the four superaspectual derivations require different morphology.

For example, the 'distributive' in $b$., which adds an emphasis on the plurality of locations at which a particular action takes place, requires the disjunct prefix ne-. The 'multiple' superaspect in $c$. also requires, at least on the surface, just the disjunct prefix yen- in order to convey a plurality of people. The 'customary' superaspect in $d$., showing habitual recurrence, however, involves the prefixation of the disjunct prefix no-, the inceptive prefix te- and an epenthetic prefix ee-, and a unique stem. The 'progressive,' on the other hand, only requires a separate stem shape. Also like aspectual derivation strings, these superaspects also impose a particular modal string. As will be visible in the next example, however, a superaspect may use one or more of these strategies, but not necessarily all.

Despite this apparent lack of structural unity, which may be mitigated slightly by assuming that all superaspects require their own stem shape, which in some cases is identical to the momentaneous, each of the superaspects to some extent share a common semantic thread of plurality. Even the 'progressive,' which is the only superaspect not to have a corresponding

\footnotetext{
${ }^{41}$ The prefix ee- can be considered a semantically empty phonological insertion, or 'epenthetic'. Its meaning is not discernible, although it accompanies the inceptive te- when it precedes some prefix ne- (Jetté, Jones, and Kari, 2000: $505)$.
} 
prefix, may be thought of as 'pluralizing' the span of activity of the verb (Axelrod, 1993: 89). They are more discernibly united, however, by their unique ability to combine with existing aspectual derivation (as seen below), and with each other.

$$
\begin{aligned}
& \text { a. yeetlyeł } \\
& y e-\quad(l e)-\varnothing-\quad(t)-\text { yet } \\
& \text { 3SG.OBJ- } \mathrm{M}_{\mathrm{PRF}^{-}} \text {-3SG.SUBJ- } \mathrm{CL}_{1} \text { - grab.SEM.PRF } \\
& \text { '(S)he grabbed it once' (theme: } \mathrm{O}+\mathrm{G}+\varnothing+\text { yetl 'grab O') } \\
& \text { b. noyegheełyetl } \\
& \text { no- ye- ghe- (n)e- ø- } \quad t-\text { yetl } \\
& \text { DS- 3SG.OBJ- } \mathrm{M}_{\mathrm{PRF}}-\text { PRF- 3SG.SUBJ- } \mathrm{CL}_{1} \text { - grab.MOM.PRF } \\
& \text { '(S)he caught it' (asp. der.: no\# gh mom. 'down') } \\
& \text { c. noyegheełyeyhtl } \\
& \text { no- ye- ghe- (n)e- } \varnothing-\quad t \text { - yeyhtl } \\
& \text { DS- 3SG.OBJ- } \mathrm{M}_{\mathrm{PRF}} \text { - PRF- 3SG.SUBJ- } \mathrm{CL}_{1} \text { - grab.CUST } \\
& \text { '(S)he customarily caught it' }
\end{aligned}
$$

The aspectual derivation 'down(wards)', which changes the meaning from that of the verb theme alone, 'grab,' to something which involves a downward movement of an object (e.g., 'catch'). Notice also that this derivational string governs the use of the stem marked for momentaneous aspect and the ghe-perfective modal string. In $c$., however, the 'customary' superaspect has overridden the previous derivation string's preferred stem, and supplanted it with its own stem. It does not affect the modal string, however, and has not added its own no- disjunct prefix to the existing no- disjunct prefix. Both levels of derivation are therefore visible. In this way, superaspects are capable of superimposing their own meaning onto an already semantically layered base. 


\subsection{Non-aspectual derivation}

Finally, there are other derivational strings which do not tend to govern the use of a particular stem. These derivational strings, called 'non-aspectual derivation' or 'post-aspect strings,' do, however, tend to govern the use of a certain modal string. In this respect, they are alike both aspectual derivational strings as well as superaspects. However, they are more related to superaspects in the sense that they may combine with aspectual derivation. There are four such non-aspectual derivations: The conative, the inceptive, the erritive, and the negative. The meaning of these sorts of derivations, as Axelrod (1993: 104) notes, is also cohesive in the sense that they convey an irrealis meaning. In other words, their meanings emphasize a contrast between what has been, or is being done, and what could have been done. Consider the following contrast.

a. eslaanh

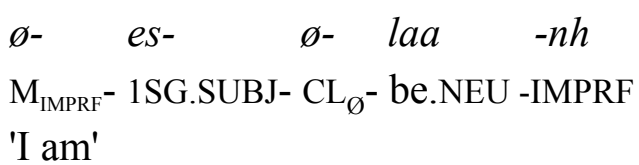

b. ooneslaa'

oo- ne- $\varnothing-\quad(e) s-\quad l a a^{\prime}$

DS- DS- $\mathrm{M}_{\mathrm{IMPRF}}-1 \mathrm{SG} . \mathrm{SUBJ}-$ be.NEU.CONA

'I am trying to be' 
The 'conative,' requiring in this case the prefixes oo- and -ne, contrast the act of attempting to be (i.e., irrealis) for actually being (i.e., realis) ${ }^{42}$. This contrast is also visible with the inceptive derivational string.

a. k'ehonh

$k^{\prime} e^{-} \quad \varnothing_{-} \quad \varnothing_{-} \quad \varnothing_{-} \quad$ hon $\quad-(n) h$

INDEF.OBJ- $\mathrm{M}_{\mathrm{IMPRF}^{-}}$3SG.SUBJ- $\mathrm{CL}_{\emptyset^{-}}$eat.DUR -IMPRF

'(S)he is eating something'

b. k'etaalhon'

$k^{\prime} e-\quad t(e)-\quad l(e)-\varnothing-\quad$ ø- hon -'

INDEF.OBJ- $\mathrm{DS}_{\mathrm{INCEP}^{-}} \mathrm{M}_{\mathrm{PRF}}{ }^{-}$3SG.SUBJ- $\mathrm{CL}_{\emptyset^{-}}$- eat.DUR -PRF

'(S)he started to eat something'

Here again, a contrast is made between doing an action and not, or, rather, starting to. A similar sort of contrast between a hypothetical point of reference and a sub-ideal actual action is the 'errative' derivational string.

a. k'egheehon'

$k^{\prime} e^{-} \quad g h e-(n) e-\varnothing-\quad \varnothing-\quad$ hon $\quad-'$

INDEF.OBJ- $\mathrm{M}_{\mathrm{PRF}}$ - PRF- 3SG.SUBJ- $\mathrm{CL}_{\emptyset}$ - eat.DUR -PRF

'(S)he ate something'

b. k'enaałdon'

$k^{\prime} e \quad n(e)-l(e)_{-}^{43} \varnothing-\quad d(e)-(h) o n \quad-'$

INDEF.OBJ- DS- $\mathrm{M}_{\mathrm{PRF}}-3$ SSG.SUBJ- $\mathrm{CL}_{\emptyset+\mathrm{D}^{-}}$eat.DUR -PRF

'(S)he overate'

\footnotetext{
${ }^{42}$ Jetté et al. (2000) list the conative as a superaspect, while Axelrod (1993) considers it a post-aspect derivation. As much of this section is based on Axelrod (1993), the latter perspective will be espoused here, although with examples, of course, from Jetté, Jones, and Kari (2000).

${ }^{43}$ It is likely that a phonological rule has devoiced the modal prefix le-before the D-effect classifier.
} 
In (49) above, the errative derivational string is conveyed by affixation of ne- a le- modal string (contrasted against the ghe- modal string of the first, underivated form), and through D-effect, denoting an effect of the action experienced by the subject. In the example above, that effect is the negative effect of having eaten too much.

Because these derivational strings account for a much of the morphology of any verb in Koyukon, and because that morphology contributes a substantial amount to the ability of Koyukon verbs to convey richly nuanced verbal meaning, a more thorough investigation, though one which extends the scope of this introductory overview, would be rewarding. 


\section{REFERENCES}

Axelrod, M. (1989). Word-based morphology: Some problems from a polysynthetic language. Colorado Research in Linguistics, 10.

Axelrod, M. (1990). Incorporation in Koyukon Athapaskan. International Journal of American Linguistics, 56(2), 179-195.

Axelrod, M. (1993). The semantics of time: Aspectual categorization in Koyukon Athabaskan. University of Nebraska Press in cooperation with the American Indian Studies Research Institute, Indiana University, Bloomington.

Axelrod, M., \& Jones, E. (1989). Determining Koyukon aspect. Alaska Native Language Center, University of Alaska, Fairbanks.

Cook, E.D. (1996). Third-Person Plural Subject Prefix in Northern Athapaskan. International Journal of American Linguistics, 62(1), 86-110.

Counceller, A. G. L., Smith, A. E., Alvanna-Stimpfle, B. Y., Charles, W., \& Olson, S. D. (2020). 2020 Biennial Report to the Governor and Legislature (p. 56). The Alaska Native Language Preservation \& Advisory Council.

Faltz, L. M. (1998). The Navajo verb: A grammar for students and scholars (1st ed). University of New Mexico Press.

Fernald, T. B., \& Platero, P. R. (Eds.). (2000). The Athabaskan languages: Perspectives on a Native American language family. Oxford University Press.

Hargus, S. (2000). The Qualifier Prefixes in Yukon Deg Xinag (Ingalik). International Journal of American Linguistics, 66(1), 1-21.

Hargus, S., \& Tuttle, S. G. (1997). Augmentation as affixation in Athabaskan languages. 
Phonology, 14(2), 177-220.

Hoijer, H. (1948). The Apachean Verb, Part IV: Major Form Classes. International Journal of American Linguistics, 14(4), 247-259.

Jette, J. (1907). 36. On the Language of the Ten'a. Man, 7, 51.

Jetté, J., Jones, E., \& Kari, J. M. (2000). Koyukon Athabaskan dictionary. Alaska Native Language Center, University of Alaska Fairbanks.

Kari, J. (1975). The Disjunct Boundary in the Navajo and Tanaina Verb Prefix Complexes. International Journal of American Linguistics, 41(4), 330-345.

Kari, J. (1981). A Symposium on Athapaskan Comparative Linguistics and Language Planning. International Journal of American Linguistics, 47(3), 265-268.

Kari, J. (1989). Affix Positions and Zones in the Athapaskan Verb Complex: Ahtna and Navajo. International Journal of American Linguistics, 55(4), 424-454.

Kari, J. (1992). Some concepts in Ahtna Athabaskan word formation. In M. Aronoff (Ed.), Morphology now. Albany, N.Y.: SUNY Press. 107-132.

Kari, J. (2000). The Koyukon verb: Jetté's terminology and contemporary terminology. In J. Kari (Ed.), Koyukon Athabaskan dictionary (pp. 753-759). Alaska Native Language Center, University of Alaska Fairbanks.

Kari, J., \& Spolski, B. (1978). 14. Trends in the Study of Athapaskan Language Maintenance and Bilingualism. In J. A. Fishman (Ed.), Advances in the Study of Societal Multilingualism. De Gruyter.

Krauss, M. E. (1968). Noun-Classification Systems in Athapaskan, Eyak, Tlingit and Haida Verbs. International Journal of American Linguistics, 34(3), 194-203. 
Krauss, M. E. (1969). On the classification in the Athapaskan, Eyak, and Tlingit Verb. International Journal of American Linguistics, 35(4), Memoir 24.

Krauss, M. E. (1992). The world's languages in crisis. Language, 68(1), 4-10.

Krauss, M. E. (2000). Koyukon dialectology and its relationship to other Athabaskan languages. In J. Kari (Ed.), Koyukon Athabaskan dictionary (pp. 1-lxv). Alaska Native Language Center, University of Alaska Fairbanks.

Pinnow, H.J. (1970). Notes on the Classifiers in the Na-Dene Languages. International Journal of American Linguistics, 36(1), 63-67.

Rice, K. (1989). A grammar of Slave. Mouton de Gruyter.

Rice, K. (2000). Morpheme order and semantic scope: Word formation in the Athapaskan verb. Cambridge University Press.

Sapir, E. (1915). The Na-Dene Languages, a Preliminary Report. American Anthropologist, $17(3), 534-558$.

Thompson, C. (1977). Koyukon Verb Prefixes. University of Alaska, Fairbanks.

Thompson, C. (1989). Pronouns and Voice in Koyukon Athapaskan: A Text-Based Study. International Journal of American Linguistics, 55(1), 1-24.

Thompson, C. (1993). The Areal Prefix ht- in Koyukon Athapaskan. International Journal of American Linguistics, 59(3), 315-333.

Thompson, C. (1996). The Na-Dene Middle Voice: An Impersonal Source of the D-Element. International Journal of American Linguistics, 62(4), 351-378.

Young, R. W., \& Morgan, W. (1987). The Navajo language: A grammar and colloquial dictionary (Rev. ed). University of New Mexico Press. 